\title{
A NMR Study of Sodium/Potassium Pumping System in the Node of Ranvier Myelin-Sheath
}

\author{
Narges Najaflou ${ }^{1}$, Majid Monajjemi ${ }^{2, *}$ (i) \\ Department of Chemistry, Science and Research, Branch, Islamic Azad University, Tehran, Iran \\ Department of Chemical Engineering, Central Tehran Branch, Islamic Azad University, Tehran, Iran \\ Correspondence: maj.monajjemi@iauctb.ac.ir;
}

Scopus Author ID:670181068

Received: 25.01.2021; Revised: 26.02.2021; Accepted: 2.03.2021; Published: 8.03.2021

\begin{abstract}
The QM/MM calculation has been applied to generalize the node of Ranvier results for computing action potentials and electrochemical behavior of membranes that agree with clusters of voltage-gated ion sodium and potassium channels. Ranvier complexes' node is an accurate organization of membrane-bound aqueous boxes. The model applied here shows an electrophysiological phenomenon with simulated structural and physiological data. The quantum effects of various thicknesses in a selected membrane of Galc /DMPC and Galc/NPGS have also been specifically investigated. This allows introducing a capacitive susceptibility that can resonate with the self-induction of helical coils or ion channels, the resonance of which is the main reason for various biological pulses.
\end{abstract}

Keywords: lipid bilayers; variable capacitors; cell membrane capacitors; node of ranvier; myelinsheath.

(C) 2021 by the authors. This article is an open-access article distributed under the terms and conditions of the Creative Commons Attribution (CC BY) license (https://creativecommons.org/licenses/by/4.0/).

\section{Introduction}

Myelin contains fatty phospholipids that are placed in a central nervous system or CNC, such as insulator environment nerve cell (axon), and increases the velocities data to crosses from one nerve cell to another tissue. [1-4] like an electrical wire (the axon) with insulating material (myelin) around it [2]. Each axon consists of several long myelinated segments where divided from each other via a short knot, called "Nodes of Ranvier" [3, 4]. A Node of Ranvier is uninsulated and fully enriched in ion channels, permitting them to interfere in ion exchange to produce sufficient action potentials. Nerves transmissions in the myelinated axons are the same as jumping due to the high action potentials from one knot to the next node [3]. In other words, reducing axonal membrane capacitance by insulating the axon increases the action potential due to large distances between the cations outside the axon and $\mathrm{Na}^{+}$that move through the axonal cytoplasm (axoplasm) [4-6]. The insulating structure for myelin is essential for seeing, hearing, feeling, the sensation of pain and perception, knowledge, and memory. Therefore, multiple sclerosis, specifically affecting the central nervous system, is related to myelin disordering $[7,8]$. The main function of myelin is preparing to accelerate to produce electrical impulses propagate along with the myelinated fiber [9]. Although in non-myelinated systems, electrical impulses produce as continuous waves, they are propagated via saltatory conduction in myelinated fibers, which is faster than continuous waves [1]. Myelin reduces the capacitor capacitance, consequently enhancing the electrical resistance across the axonal membrane [10]. Voltage-gated sodium channels are enough at each node of Ranvier, $\mathrm{Na}^{+}$can 
enter inside the axon through high activated voltage in a channel, leading to depolarization of the cell membrane at each node [11]. This potential is then quickly repaired due to $\mathrm{K}+$ ions leaving the axon via potassium channels. The $\mathrm{Na}+$ quickly diffuses through the axoplasm to the inter-node and then to the next Ranvier node to open the related channel at this site [12]. The action potentials among the adjacent nodes should not be less than +30 millivolts [11] During the myelinated internode, energies of sodium/potassium pumping system, the Na+ come back out of the axon, and $\mathrm{K}+$ come back into the axon for tuning the equilibrium of ions among the intracellular (Scheme 1).

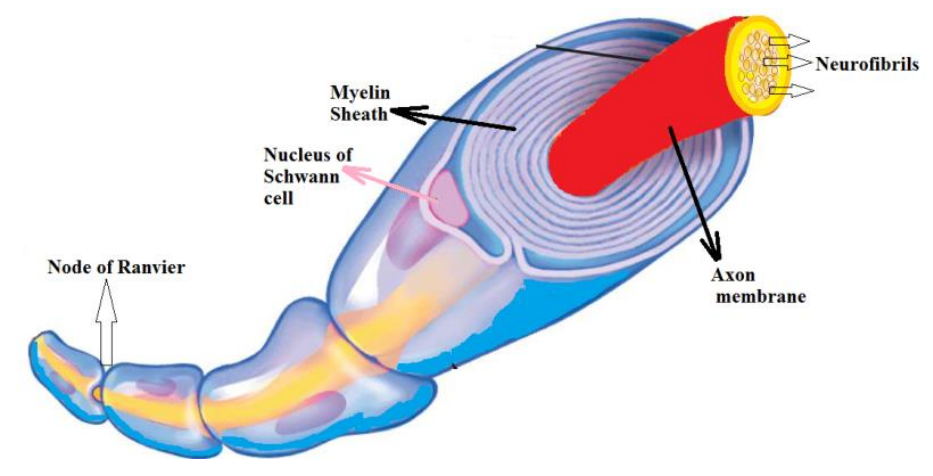

(a)
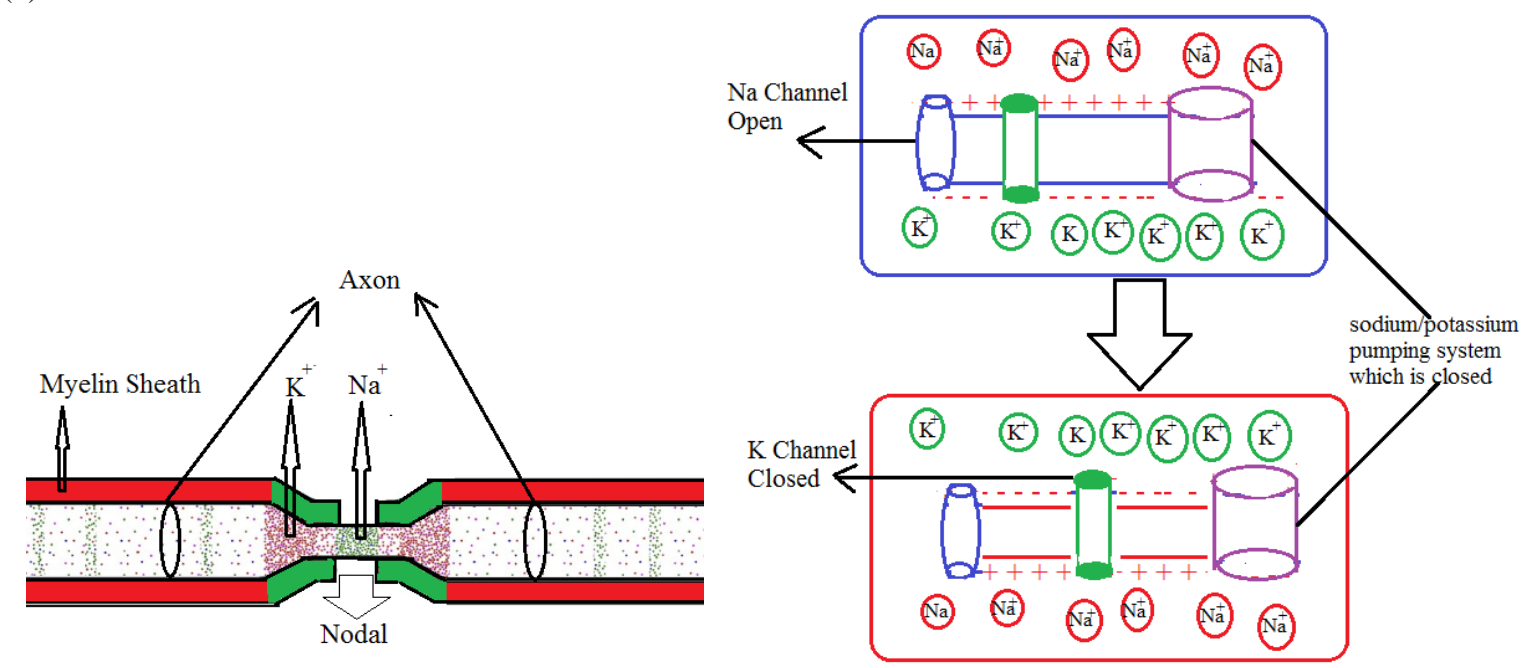

(b)

Scheme 1. (a) Neuron; (b) sodium/potassium pumping system.

The NOR consists of "Na+/K+ ATPases", "Na+/Ca2+" , and large densities of voltagegated $\mathrm{Na}+$ channels, where prepare suitable potential for any further electrical pulses. The sodium channel consists of two alpha and beta subunits that anchor the channel for intra- and extra- cellular ingredients. The extra region of the beta subunit can be associated with itself and some other components such as "Contactin protein," which causes to increase in the area expression of $\mathrm{Na}+$ channels [13].

\section{Materials and Methods}

\subsection{Electromechanical pulses.}

Neurons transmit data via the electrical waves that appear as action potential and have a range of velocities among 1 to $100 \mathrm{~m} / \mathrm{s}$. Neurons receive those pulses from dendrites and then propagate them inside the axons for any connection to other cells electrically ( sometimes chemically) — consequently several neurons with special electrochemical behaviors embedded inside the glycolipids. Axon membrane consists of some types of proteins that selectively transfer $\mathrm{Na}$ and $\mathrm{K}$ ions in a 
suitable voltage.Therefore, this model exhibits an electrical circuit in which the proteins are resistors, and the membrane is a capacitor. Ions flow along the membrane and nerve axon due to the voltage changes. Nerves represent thickness and length variations under the influence of the action potential $[14,15]$. In addition, the action potential might be excited through the heat during the nerve pulses or even a mechanical stimulus. Moreover, the pulses can also be stimulated via local cooling, indicating that heat changes occur at any time of action potential [16].

Consequently, the pulses can be moving the same as the velocity of sound in the membrane. Hodgkin [17] interpreted; action potential is related to reducing the membrane potential and is based on overshooting action potential due to increasing sodium permeability. They studied a voltage-clamp circuit model to facilitate qualities and quantities testing of ionic currents from squid axon. They also exhibited where membranes situation via a selective position allowed the transition of sodium or either potassium in an activated voltage [18]. In an ionic swapping, the pure current might be divided into fast inward current carried by $\mathrm{Na}+$ ions and the slow-activated outward current carried by $\mathrm{K}+$ ions[19], which are results from independent permeation mechanisms for sodium and potassium ions in the membrane (Scheme 2) [20]. Several ion currents share the voltage signal of each neuron that three of them are root sections as instant: sodium current, potassium current, leak current. Their flow is controlled through their respective voltage's channels in a membrane. The semipermeable membrane separated the interior from the exterior layers. The phospholipid membranes are modeled as insulators that act similarly a capacitor with variable capacitance while each protein as resistance has a specific conductance. By changing of voltage, two currents can be produced, first one is a capacitive current and the second one is ohmic currents that are against the proteins resistances and total current is the sum of these two type of currents.

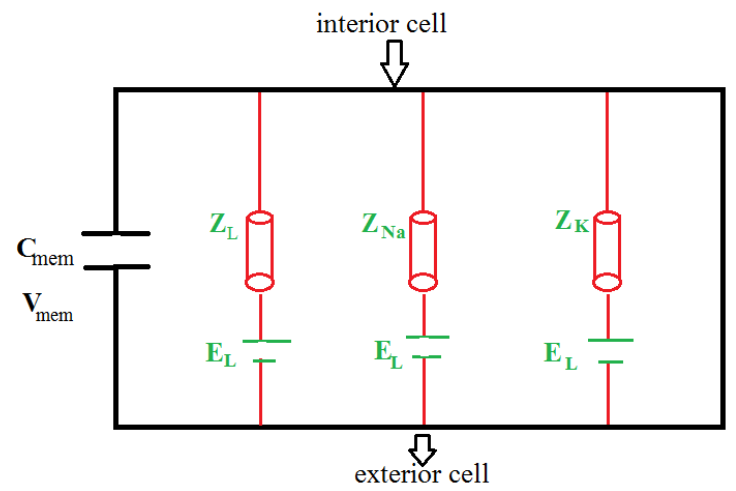

Scheme 2. Sodium and potassium channels as resistance in the circuit of membranes.

$I_{m e m}$, is given by: $I_{m e m}(t)=C_{m e m} \frac{d V_{m e m}}{d t}+Z_{N a}\left(V_{m e m}-E_{N a}\right)+Z_{K}\left(V_{m e m}-E_{K}\right)+$ $Z_{\text {Leak }}\left(V_{\text {mem }}-E_{\text {Leak }}\right)(1)$ where $E_{N a}, E_{K}$ and $E_{\text {Leak }}$ are the Nernst potentials and is given by equation $E_{i}=\frac{R T}{z F} \operatorname{Ln} \frac{C_{\text {out }}}{C_{\text {in }}}$ where $C_{\text {out }}$ and $C_{\text {in }}$ are both inside and outside cell concentrations of ions. This relation exhibits that current flows due to diffusion gradients and consequently if the external voltage is equal to the Nernst potential, no current flows. Using Kirchhoff's laws, "cable theory", it is possible to image the prediction of a voltage along a cylindrical membrane as a function of distance $\mathrm{x}$. The propagating action potential can be estimated by: $\frac{\partial^{2} V_{m e m}}{\partial x^{2}}=$ $\frac{2 R_{i}}{\alpha} I_{m}$ where $R_{i}$ is the specific inner resistance of the intracellular medium along the cable or through combining Eq. (1) with "cable theory", the equation (2) is given as follows [21,22]: 
$\frac{\partial^{2} V_{\text {mem }}}{\partial x^{2}}=\frac{2 R_{m e m}}{\alpha}\left(C_{\text {mem }} \frac{d V_{\text {mem }}}{d t}+Z_{N a}\left(V_{\text {mem }}-E_{N a}\right)+Z_{K}\left(V_{\text {mem }}-E_{K}\right)+Z_{\text {Leak }}\left(V_{\text {mem }}-E_{\text {Leak }}\right)\right.$

(2) And $R_{m e m}$ is the specific resistance of the membrane. If it supposes the pulse propagates with a constant speed " $\theta$ " which is independent of voltage, consequently, the time-dependent wave equation can be rewritten as: $\frac{\partial^{2} V_{m e m}}{\partial t^{2}}=\theta^{2} \frac{\partial^{2} V_{m e m}}{\partial x^{2}}$ (3). Combining Eq. (2) with Eq. (3) yields the propagation of the electrical pulse equation [23,24]:

$\frac{\partial^{2} V_{m e m}}{\partial t^{2}}=\theta^{2} \frac{2 R_{m e m}}{\alpha}\left(C_{m e m} \frac{d V_{m e m}}{d t}+Z_{N a}\left(V_{m e m}-E_{N a}\right)+Z_{K}\left(V_{m e m}-E_{K}\right)+\right.$

$Z_{\text {Leak }}\left(V_{\text {mem }}-E_{\text {Leak }}\right)$ (4). for the mathematical treatment of action potential propagation along GalC of myelinated axons, we simulated a hybrid system of active elements coupled by passively conducting cables. A mathematical equation is described as;

$C_{g a l} \frac{\partial v}{\partial t}=\frac{1}{R_{c}} \frac{\partial^{2} V}{\partial x^{2}}-\frac{V}{R_{g a l}}+I_{c h a n}(v, t)(5)$, here $C_{g a l}$ and $R_{g a l}$ are the (radial) capacitance and resistance of a myelinated fiber including Galactocerebroside, and $R_{c}$ is its axial resistance. [17].

\subsection{Membrane consists of Galactocerebroside as a capacitor.}

The primary lipid of myelin is Galactocerebroside, which is a type of cerebroside including of ceramide with a galactose residue [25] (Figure 1). Pascher [26, 27], via X-ray diffraction of cerebroside, exhibited that cerebroside bilayers' structure has been built up through the galactose and several hydrogen bonds, including donor and acceptor groups $(\mathrm{CO}, \mathrm{NH}, \mathrm{OH})$ permit the formation of numerous bonding. Additionally, anhydrous and hydrated cerebroside (N-palmitoyl galactosyl sphingosine) or NPGS confirm evidence of complex polymorphic treatment. Some studies have reported the manner of mixtures of human spleen dimyristoylphosphatidylcholine (DMPC) and mixtures of bovine brain cerebrosides [28, 29]. Correa [28] suggests that glucocerebroside distribution is affected via the lipid bilayer's physical state and by the glucocerebroside/DMPC (or DPPC) molar ratio. [30]. Although neither NPGS nor DPPC is a main constituent of myelin, their mixture with GalC does permit a detailed structural analysis of their mutual interactions.

GalC and sulfatide have major roles in Peripheral myelin structure and are also followed by microtubule depolymerization. The cable equation of currents along GalC of myelinated axons yields a dynamics behavior. By this works, a small piece of cell membrane including pure GalC, DMPC, DPPC, and a mixing of GalC/DPPC, GalC/DMPC, and GalC/NPGS with 50 to $70 \%$ mol ratio of each have been simulated (Figure 2).

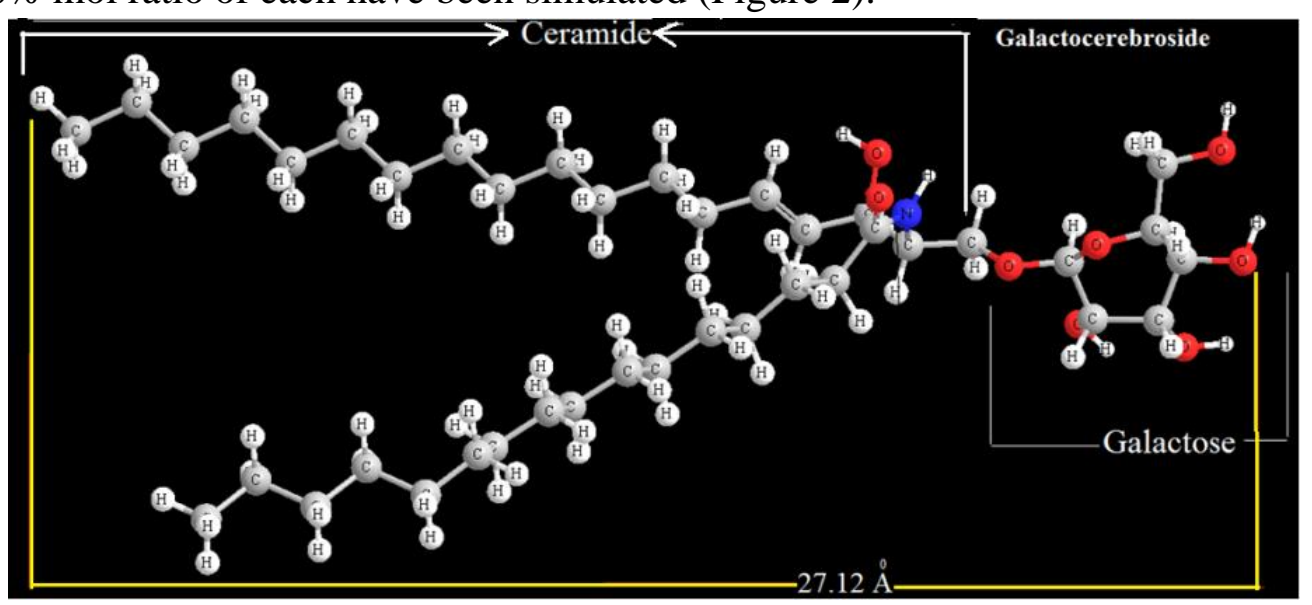

Figure 1. Optimized molecule of Galactocerebroside (GalC) with cam-b3lyp/cc-pvdz basis set. 


\subsection{Membrane capacitor model.}

During a neuron's growth, cell diameter can change considerably, and neuronal elasticity may cause changes in the cell surface. Membrane capacitance is the main parameter for measuring cellular properties based on size changes. For example, occasionally, conductance densities for removing potential effect changes in neuronal size to predict the correct mechanism have been calculated. Several experimental activities exist to determine the total membrane capacitance and are similar in most cells [31]. The capacitance may be calculated from the rate and amplitude changes in the voltage responses based on the voltage clamp. These ways are applied widely to determine the total capacitance of several neurons membrane. By this work, we simulated our systems based on several membrane thicknesses in the viewpoint of capacitors.

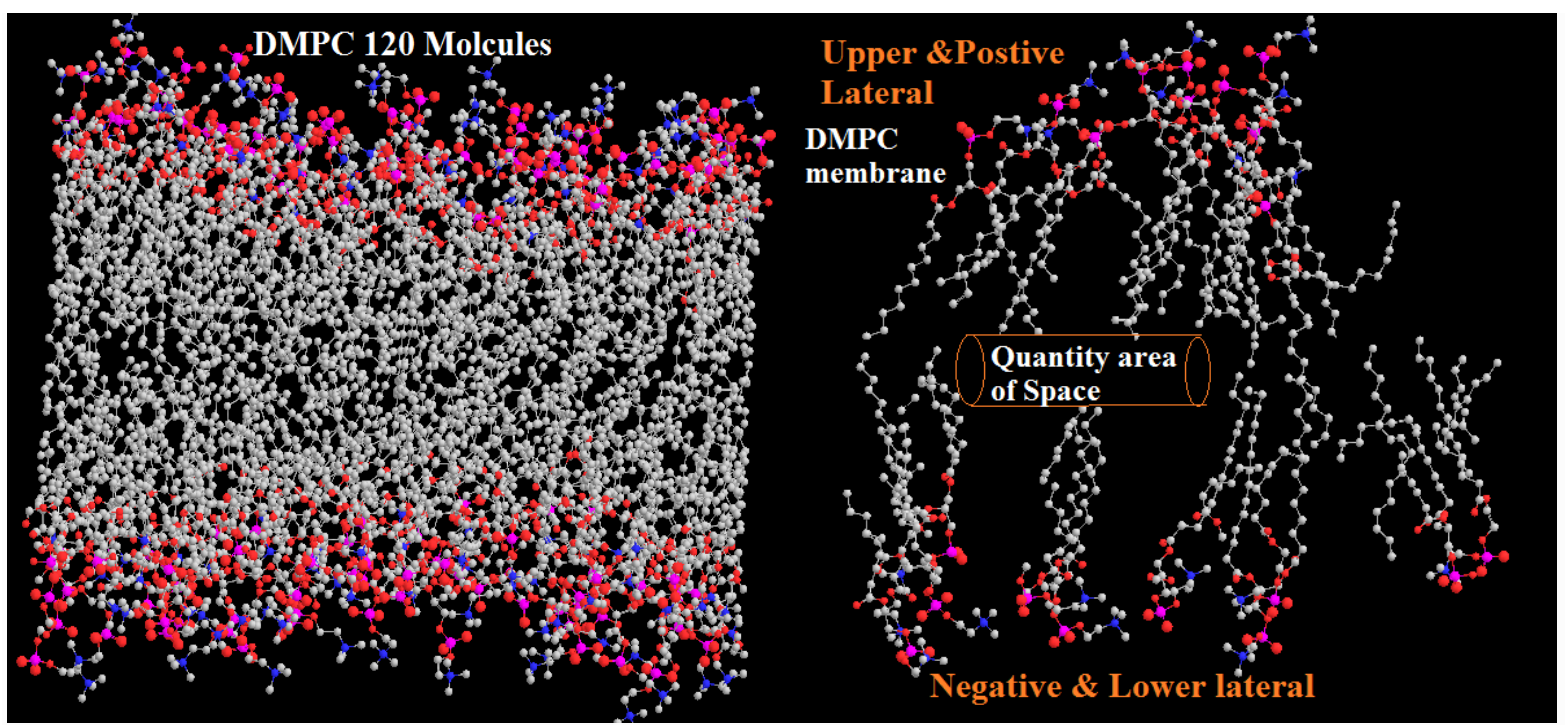

Figure 2. Monte Carlo calculation of several phospholipids.

We compared the capacitance values of identified neuron cell membranes, including GalC, DMPC, DPPC, and also a mixing of GalC/DPPC, Galc/DMPC and Galc/NPGS (Figure 3). It has been shown these results yield suitable exponential voltages, which are fitted by DC current in total membrane capacitance over vast ranges of cell sizes have been simulated. The results in a membrane potential change characterized by a single exponential (Eq. 6) with a time constant, $\tau_{\text {mem }}=r_{\text {mem }} C_{\text {mem }}$ where $r_{\text {mem }} C_{\text {mem }}$ indicate the cell membrane resistance the total membrane capacitance, respectively. In such an isovoltage cell, $r_{\text {mem }}$ is equal to the cell's input resistance $R_{\text {in }} V_{\text {mem }}(t)=V_{\text {rest }}+\sum_{i=0}^{\infty} V_{i}\left(1-e^{-\frac{t}{\tau_{i}}}\right)(6)$, the maximum membrane potential change is given by $\Delta V_{\text {mem }}=V_{\text {mem }}-V_{\text {rest }}=R_{\text {in }} . I_{\text {ext }}$ (7) where $\mathrm{I}_{\text {ext }}$ is injected current phase [32].

Generally, only two or three terms adequately describe $V_{\text {mem }}(t)$, given by the equation (6) (Fig.4). Through dividing "Iext" to a series of resistive terms as $R_{i}=\frac{V_{i}}{I_{\text {ext }}}$ steady-state can be evaluated as the sum of these resistive terms" $R_{\text {in }}=\frac{\Delta V_{\text {mem }}}{I_{\text {ext }}}$ ". The time constant of the slowest exponential $\left(\mathrm{e}^{-\mathrm{t} / \tau=0}\right)$ corresponds to the membrane time constant $\tau_{m}=r_{m} C_{m}$ [34]. 

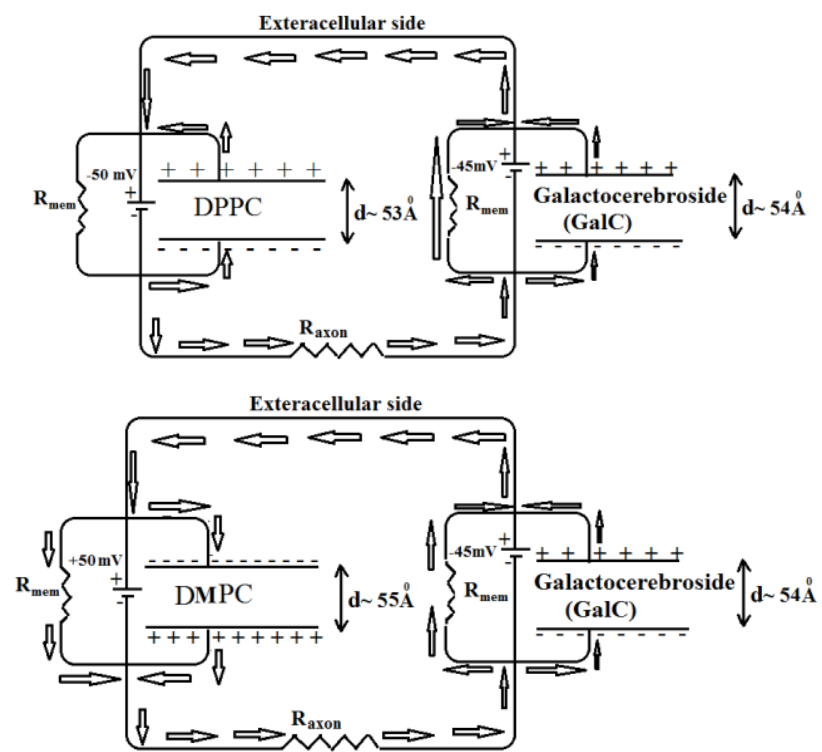

Figure 3. DPPC, DMPC, GaLC in a circuit related to their thickness and their voltages.

For determining the values of $V_{i}$ and $\tau_{i}$, the $V_{\text {mem }}(t)$ might be fitted using the LevenbergMarquardt (LM) algorithm. For calculating the suitable data, the fitting has been done between $t=0$ and when the voltage had reached a steady state. The capacitance, current, and voltage can be calculated through the following equations $Q=C_{m e m} \Delta V_{m e m}=\int_{0}^{t_{s t e p}} I_{c} d t$.

Consequently, $C_{m e m}$ can be calculated according to $I_{C}=\frac{d Q}{d t}=C_{m e m} \frac{d V_{m e m}}{d t}$ (9) where $\frac{d V_{m e m}}{d t}$ is slope of the voltage curve.

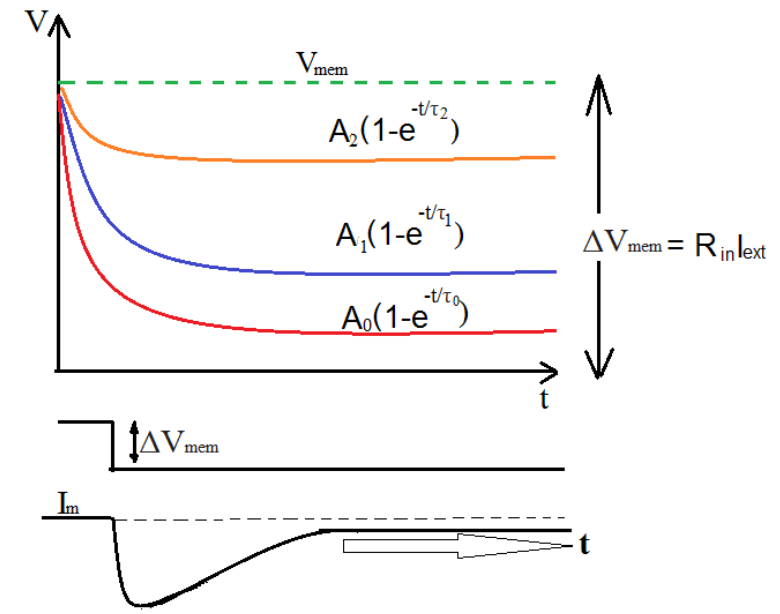

Figure 4. Schematic diagrams representing the membrane potential change, voltage-clamp step and the charge deposited on the membrane for a given " $V_{\text {mem }}$ ".

GalC/DPPC, Galc/DMPC and Galc/NPGS, variable capacitance, $C_{m e m}(t)$, defines the amount of charge $(\mathrm{Q})$, as a function of time $V_{\text {mem }}(t)$ Fig.3Obviously, because of nanoscale characteristics in the cell membrane, quantum electrical properties might be considered. In a thin-membrane cell, this indicates that the geometric capacitance of the mentioned membranes, $C_{m e m}^{g e o}$, is related to the different voltages, " $\Delta V_{m e m "} \quad C_{m e m}^{g e o}=\frac{\sigma}{\Delta V_{m e m(t)}}=\frac{\varepsilon_{r} \varepsilon_{0}}{d_{m e m(t)}}$ (10).

Supposing that each capacitor plates carry $\pm Q$ charges from the positive side to the negative side, the initial energies stored in an electrostatic field over the capacitor electrodes is given by $E_{i}=\frac{Q^{2}}{2 C_{m e m}}$. And for those systems that the charge $\left(Q+\Delta q_{e}\right)$ resides on the top 
plate and $\left(-Q-\Delta q_{e}\right)$ resides on the bottom plate, the accumulated energy is equal to" $E_{f}=$ $\frac{(Q+\Delta q)^{2}}{2 C}$ ". and $\Delta E_{S}=E_{f}-E_{i}=\frac{\Delta q\left(Q+\frac{\Delta q}{2}\right)}{C}$ (11). In this situation, the maximum voltage occurs in the range of $-\frac{\Delta q_{\text {mem }}}{2 C_{\text {mem }}}<\Delta V_{\text {mem }}<+\frac{\Delta q_{\text {mem }}}{2 C_{\text {mem }}}$ where the tunneling current would only flow if the voltage is sufficiently large, i.e., $\left|\Delta V_{\text {mem }}\right|>\left|\frac{q_{m e m}}{2 C_{m e m}}\right|$. This effect is known as the Coulomb blockade [35].

Based on the fluid mosaics model of lipids, the dielectric constant for the abovementioned membrane changes from time to time, while the changes in capacitances are not rapid. Quantum effects in the membrane imply that the membrane's capacitances are larger than the membrane's geometry. Thus, any bio-membrane phenomenon related to the dynamic situation, such as physiology temperature, will influence their capacitances. It is also notable that the cellular electrical properties and electromagnetic fields on cells result in the electro biological mechanism. It is also exhibited that the quantum effects are able to change the membrane's capacitances due to the external effects. Besides, it is also concluded that the membranes' electrical properties are affected via the application of electron densities in the membranes mentioned above. Our previous works have been declared [36- 65] that the quantum components manifest the density of states (Dos) of the phosphate or galactose groups and their Thomas-Fermi screening lengths. Hence, the hybrid capacitance of any Nanocapacitor architecture is as follows:

$$
C_{\text {mem }}=\left(\frac{1}{c_{\text {mem }}^{\text {Qua }}(\text { one hand })}+\frac{1}{c_{\text {mem }}^{\text {geo }}}+\frac{1}{c_{\text {mem }}^{\text {Qua }}(\text { opposite hand })}\right)^{-1}
$$

(14) where $c_{m e m}^{\text {Qua }}$ (top side) and $c_{\text {mem }}^{q u a}$ (down side) are the quantum capacitances due to the finite Dos of the phosphate group's electrodes, respectively, as illustrated in Figure 5.

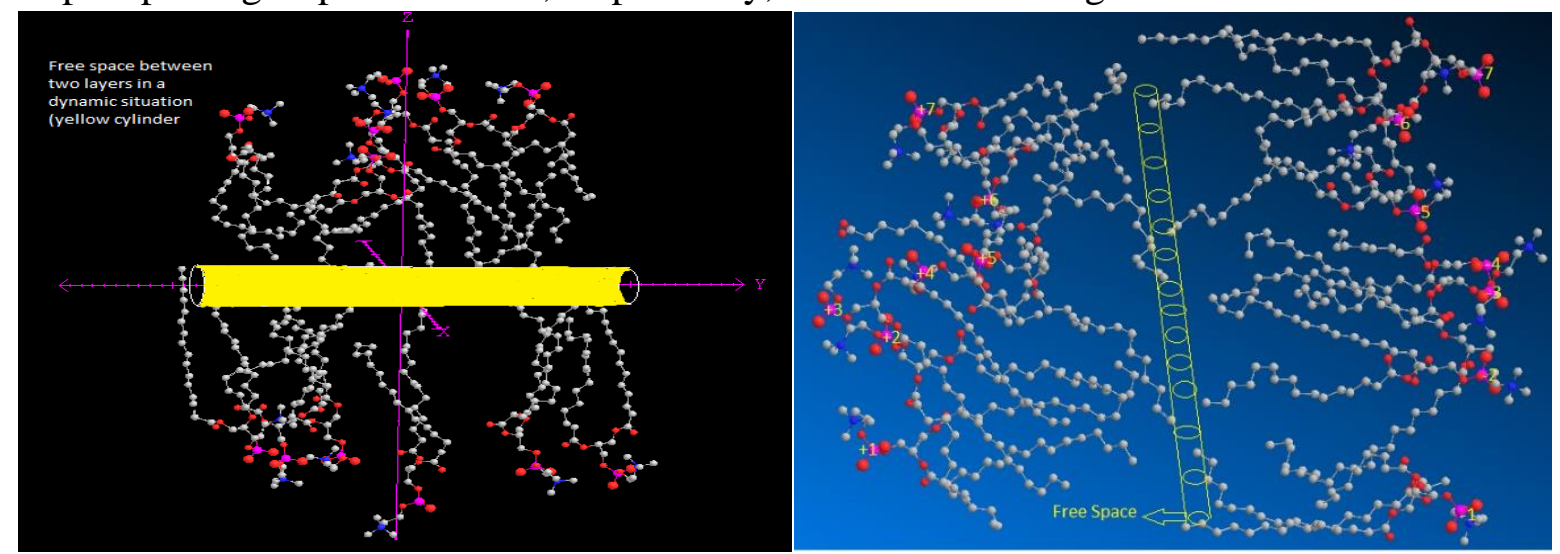

Figure 5. Free space between two layers in a dynamic situation due to tunneling coulomb blockade effect.

A change in voltage leads to a capacitive current due to the changes in the charge on the capacitor, which is given by: $\frac{d Q}{d t}=\frac{d}{d t}\left[\left(C_{m e m} \cdot V_{m e m}\right]=C_{m e m} \frac{d V_{m e m}}{d t}+V_{m e m} \frac{d C_{m e m}}{d t}\right.$ and $\frac{d C_{m e m}}{d t}=f\left(\frac{d C_{m e m}^{g e o}}{d t}, \frac{d C_{m e m}^{q u a}}{d t}\right)$

Heimburg exhibited that the changing voltages during the nerve pulses are completely dependent on the capacitances changing. Also, transition voltages can exchange the ions. They have also exhibited how the membranes' electrical properties are affected by the application of lateral pressure or tension in a membrane. By supposing that the $C_{m e m}^{g e o}$ of bio-cell membranes (in contrast of $C_{m e m}^{q u a}$ ) is independent of voltage and depends on the geometry, the second term on the right side of eq.15 is a quantum effect $\left(\frac{d C_{m e m}^{g e o}}{d t}=0\right)[4]$. 


\subsection{NMR shielding.}

The reduced anisotropy $\left[\zeta=\left(\sigma_{z z}-\sigma_{i s o}\right)=\left(\sigma_{33}-\sigma_{i s o}\right)\right](\mathbf{1 6})$ and anisotropy $(\Delta \sigma)$ with the relation of $\Delta \sigma=\frac{3}{2} \zeta$ including shielding asymmetry $(\eta)$ can be defined as:

$$
\Delta \sigma=\sigma_{z z}-\frac{1}{2}\left(\sigma_{x x}+\sigma_{y y}\right) \quad(\mathbf{1 7}) \quad \text { and } \eta=\left(\frac{\sigma_{y y}-\sigma_{x x}}{\zeta}\right)=\frac{3\left(\sigma_{y y}-\sigma_{x x}\right)}{2 \Delta \sigma}
$$

Spherical tensors are intrinsically involved in considering the effects of tensor quantities on density matrix evolution, so it is worth noting that:

$$
\sigma_{0}^{i s o(2)}=\sqrt[2]{3 / 2} \zeta \quad \text { (19) } \quad \text { And } \quad \sigma_{ \pm 2}^{\text {sym(2) }}=\frac{1}{2} \zeta \quad(\mathbf{2 0}) \text {. }
$$

The symmetric component of the shielding tensor has tensor elements with $r_{i j}=r_{j i}$. This tensor is responsible for the CSA relaxation most often described in the literature and can be diagonalized by rotation into the shielding tensor principal coordinate system. The antisymmetric tensor also induces CSA relaxation, but this is almost impossible to measure because the induced effects are close to parallel to the external magnetic field, which cannot be diagonalized. Therefore, it is represented by a tensor of Span

$$
(\Omega)=\sigma_{33}-\sigma_{11} \text { and } \kappa=\frac{3\left(\sigma_{i s o}-\sigma_{22}\right)}{\Omega}(\mathbf{2 1}) \text {. }
$$

In this study, we consider a model of sodium/potassium using ab-initio calculations within the density functional theory (DFT) for calculating the aromaticity of rings for organic calculations.

\subsection{Computational details.}

A major part of the membrane systems, including GalC/DPPC, GalC/DMPC, and GalC/NPGS have been modeled with OMIOM (QM/MM) and the Monte Carlo method. The temperatures were fixed between $300 \mathrm{~K}-310 \mathrm{~K}$ where the biological ranges were identical to the relevant experiments. The configuration of individual lipids consistent with a mean-field was generated by the Monte Carlo (MC) simulation, with field values adjusted for obtaining acceptable experimental order data. In this work, several force fields are applied with AMBER and Charmm software, and, in addition, the Hyper-Chem professional release 7.01 programs are used to draw the graphs of simulation. All optimization of monomer molecules of each membrane was performed through Gaussian 09. This study's main focus is to obtain the results from DFT methods such as m062x, m06-L, and m06 for the (Myelin's lipids molecules) $n$ n $=1$ 10\}. The m062x, m06-L and m06-HF are advanced and novel functional with a suitable correspondence in non-bonded calculations between GalC/DPPC, GalC/DMPC, and GalC/NPGS monomers and are useful for determining the voltages in the viewpoint of distance differences distance between two lateral in two sides of myelin's lipids. For non-covalent interactions between two layers of membranes, the B3LYP method is not suitable for describing van der Waals forces via medium-range interaction. Therefore, the QM/MM (ONIOM) methods, including three sections of high (H), medium (M), and low (L) levels of calculations, have been performed. For the first layer of ONIOM (QM/MM), DFT methods and the second layer semi-empirical pm6 (including pseudo=lan12) and the third layer $\mathrm{Pm}_{3} \mathrm{MM}$ are applied for the high, medium, and low sections, respectively. The interaction energies for membrane capacitors were measured as follows: 
$\left.E_{S}(e V)=\left\{E_{C}-\left(\sum_{i=1}^{n}(\text { Positive Myelin's lipids })_{i}+\sum_{i=1}^{n} \text { (Myelin's lipids }\right)_{i}\right)\right\}+E_{B S S E} \quad S^{\prime \prime}$ is the stability energies of the membrane capacitor.

\section{Results and Discussion}

\subsection{Myelinated axon simulation.}

We used model descriptive structures of several membranes, including GalC/DPPC, GalC/DMPC, and GalC/NPGS with the simplest consisting of two spheres attached to the related ends of a cable, which denote neuritis $\left(l_{\text {length }} \& d_{\text {diameter }}\right)$. We modeled variations in neuronal component size by changing, $l_{\text {length }} \& d_{\text {diameter }}$ (Table.1). In our model, the myelinated axon is a nearly circular profile surrounded by a spirally wound multilamellar sheath and has been wrapped with a medium number $(n=100)$ of the myelin sheath (Table 1$)$.

Table 1. Geometries of Ranvier node, myelin, and myelin-sheath based on Monte Carlo and QM/MM calculation.

\begin{tabular}{|c|c|c|c|c|c|c|c|c|}
\hline \multirow[b]{2}{*}{ Membrane } & & \multirow[b]{2}{*}{$\begin{array}{l}C_{\text {axon }} \\
\mu F \\
/ \mathrm{cm}^{2}\end{array}$} & \multirow[b]{2}{*}{$\begin{array}{c}\text { Dielectric } \\
\text { Constant } \\
K_{\text {mem }} \\
\end{array}$} \\
\hline & $\begin{array}{c}d_{\text {node }} \\
n=12 \\
(\mu m)\end{array}$ & $\begin{array}{c}d_{\text {myelin }} \\
\boldsymbol{n}=120 \\
(\boldsymbol{\mu} \boldsymbol{m})\end{array}$ & $\begin{array}{c}\boldsymbol{d}_{\text {myelin-sheath }} \\
\boldsymbol{n}=\mathbf{1 0 0} \\
(\AA)\end{array}$ & $\begin{array}{l}l_{\text {node }} \\
(\boldsymbol{\mu m})\end{array}$ & $\begin{array}{c}l_{\text {myelin }} \\
(\boldsymbol{\mu m})\end{array}$ & $\begin{array}{l}C_{\text {nodal }} \\
\mu F \\
/ \mathrm{cm}^{2}\end{array}$ & & \\
\hline GalC/DPPC & 0.20 & 0.65 & $56 / 55$ & 0.60 & 1.64 & $2.2^{*}$ & 0.45 & 6.10 \\
\hline GalC/DMPC & 0.15 & 0.45 & $53 / 54$ & 0.70 & 1.60 & 2.15 & 0.55 & 5.40 \\
\hline GalC/NPGS & 0.10 & 0.75 & $58 / 50$ & 0.50 & 1.55 & 2.17 & 0.40 & 4.45 \\
\hline
\end{tabular}

The expected thickness of alkyl's layers between those membrane plates has been estimated, optimized, and applied as an excellent model of dielectric constant for those capacitances calculations (Table 2).

Table 2. Dielectric constant, capacitance, and stability energies of various modeled membrane capacitors in various thicknesses for GalC/DPPC capacitor.

\begin{tabular}{|c|c|c|c|c|c|c|}
\hline $\begin{array}{c}\text { GalC/DPP } \\
\text { C \& } \\
\text { Number of } \\
\text { atoms }\end{array}$ & $\begin{array}{l}\Delta E_{S} \\
(e V)\end{array}$ & $\begin{array}{c}\Delta V= \\
\Delta\left(\sum \boldsymbol{V}_{\boldsymbol{P}_{+}}^{1 \text { toN }}-\sum \boldsymbol{V}_{\boldsymbol{P}_{-}}^{1 \text { toN }}\right)\end{array}$ & $\begin{array}{c}\Delta \boldsymbol{Q}= \\
\Delta\left(\sum \boldsymbol{Q}_{\boldsymbol{P}_{+}}^{1-N}-\left|\sum \boldsymbol{Q}_{\boldsymbol{P}_{-}}^{1-N}\right|\right)\end{array}$ & $\begin{array}{c}\text { expectation } \\
\text { of dielectric } \\
\text { thickness }\end{array}$ & $\begin{array}{l}C_{g}(F) \\
\times 10^{20}\end{array}$ & $\begin{array}{l}\text { Dielectric } \\
\text { Constant }\end{array}$ \\
\hline$(\mathrm{N}=60)$ & 0.0 & - & - & - & - & - \\
\hline$(\mathrm{N}=120)$ & +0.40 & 3.0 & 1.1 & 39.33 & 2.0 & 7.4 \\
\hline$(\mathrm{N}=240)$ & +1.15 & 3.5 & 1.4 & 38.23 & 4.8 & 7.2 \\
\hline$(\mathrm{N}=300)$ & 0.85 & 4.2 & 1.6 & 40.31 & 1.5 & 6.4 \\
\hline$(\mathrm{N}=360)$ & +0.55 & 5.0 & 1.5 & 39.01 & 1.3 & 4.12 \\
\hline$(\mathrm{N}=520)$ & 0.55 & 5.1 & 1.9 & 39.44 & 1.4 & 6.11 \\
\hline$(\mathrm{N}=1000)$ & 1.15 & 5.3 & 1.8 & 40.25 & 1.1 & 5.29 \\
\hline
\end{tabular}

Same as other capacitors, the an-isotropic attachment of alkyl groups allows the formation of several layered structures. Long-ranges interlayers interactions play a prevailing role in characterizing those systems' electrical and mechanical properties and hence their efficiency in these capacitors' models. The calculated values of the structure of the lipids such as distances between two layers, dielectric constants, (k), the magnitude of the charges on each side of membranes, electrostatic properties using the SCF densities, fitting potential charges from ESP, stabilities energies of GalC/DPPC, GalC/DMPC and GalC/NPGS as the capacitors, are listed in Tables $2 \& 3$. The potential between two layers, $\Delta V=\Delta\left(\sum V_{P_{+}}^{1-N}-\sum V_{P_{-}}^{1-N}\right)$ (a.u.) are listed in Table 3. 
Table 3. The dielectric and capacitance $\mathrm{C}_{\mathrm{Q}}=$ quantum capacitance, $\mathrm{C}_{\mathrm{g}}=$ geometry capacitance, and $\mathrm{C}_{\text {net }}=$ net capacitance modeled of GalC/DPPC capacitor in various thicknesses.

\begin{tabular}{c|c|c}
$\begin{array}{c}\text { GalC/DPPC \& Number } \\
\text { of atoms }\end{array}$ & $\begin{array}{c}\boldsymbol{C}_{\boldsymbol{Q}}(\boldsymbol{F}) \times \mathbf{1 0}^{\mathbf{1 9}} \\
=\frac{\Delta \boldsymbol{q}\left(\boldsymbol{Q}+\frac{\Delta \boldsymbol{q}}{\mathbf{2}}\right)}{\Delta \boldsymbol{E}_{\boldsymbol{S}}}\end{array}$ & $\begin{array}{c}\boldsymbol{C}_{\boldsymbol{n} \text { et }}(\boldsymbol{F}) \times \mathbf{1 0}^{\mathbf{1 9}}= \\
\frac{\boldsymbol{C}_{\boldsymbol{g}} \boldsymbol{C}_{\boldsymbol{Q}}}{\boldsymbol{C}_{\boldsymbol{Q}}+\mathbf{2} \boldsymbol{C}_{\boldsymbol{g}}}\end{array}$ \\
\hline$(\mathrm{N}=400)$ & 1.45 & 1.35 \\
\hline$(\mathrm{N}=500)$ & 1.15 & 0.97 \\
\hline$(\mathrm{N}=1000)$ & 1.46 & 1.22 \\
\hline$(\mathrm{N}=1500$ & 1.49 & 0.99
\end{tabular}

The nano-capacitances of $C_{g}, C_{Q}$ and $C_{n e t}$ for GalC/DPPC, GalC/DMPC and GalC/NPGS in different dielectrics thickness are listed in Table 3. Although the dielectric strength can be deduced from an alkyl space filler's bandgap, the dielectric constant is directly calculated from eq. 5, which is much more accurate than the other ways. This conformability is not valid for short distances due to the quantum effect. Therefore the dielectric permittivity as a function of dielectric size has been defined through, $C_{Q}(F) \times 10^{20}=$ $\frac{\Delta q\left(Q+\frac{\Delta q}{2}\right)}{\Delta E_{S}}$ and $C_{n e t}(F) \times 10^{20}=\frac{C_{g} C_{Q}}{C_{Q}+2 C_{g}}$. In the presence of any fields, myelin's protein, including trance membrane or potassium or sodium channel ions, charges employ the forces which can influence the position of the membrane in the myelin; thereby influencing the variable fields makes variable capacitances in the membrane systems of GalC/DPPC, GalC/DMPC, and GalC/NPGS. This effect allows one to introduce a capacitive susceptibility that resonates with helical coils' self-induction effect in myelin's proteins. Table 4 exhibits the calculated helical proteins self-induction of myelin's proteins via resonance with the capacitance of the GaLC/DPPC lipids or other myelin membrane's lipids (Figure 8). Coils have greater inductance than straight conductors. Thus, in biological phenomena, a helical coil of trance myelin's proteins resonate with a capacitive susceptibility of lipids capacitors of GalC/DPPC, GalC/DMPC.

\subsection{NMR analysis.}

Total shielding constants, orientations of the principal axes such as standard components, Haeberlen-Mehring, and Herzfeld-Berger parameters for sodium/potassium systems in various statistical situations have been calculated using DFT methods and the data are listed in Tables 4-6.

Table 4. NMR parameters of sodium/potassium systems in both isolated and Ranvier myelin sheath media.

\begin{tabular}{c|c|c|c|c|c|c|c|c|c} 
Atom & $\boldsymbol{\sigma}$ Iso & $\boldsymbol{\sigma}$ Aniso & $\boldsymbol{\sigma}$ & $\boldsymbol{\sigma} \mathbf{1 1}$ & $\boldsymbol{\sigma} \mathbf{3 3}$ & $\boldsymbol{\Delta}$ & $\boldsymbol{\delta}$ & $\boldsymbol{\eta}$ & Charge \\
\hline $\mathrm{K}(1)$ & $248 / 6986$ & $50 / 2568$ & $225 / 0971$ & $238 / 7955$ & $282 / 2031$ & $50 / 2568$ & $33 / 5045$ & $0 / 408853$ & $-0 / 13825$ \\
\hline $\mathrm{Na}(2)$ & $245 / 2793$ & $48 / 1205$ & $221 / 2316$ & $237 / 2468$ & $277 / 3597$ & $48 / 1205$ & $32 / 0804$ & $0 / 499221$ & $-0 / 13938$ \\
\hline $\mathrm{K}(3)$ & $240 / 3852$ & $48 / 7446$ & $204 / 6772$ & $243 / 5968$ & $272 / 8816$ & $-53 / 562$ & $-35 / 708$ & $0 / 820119$ & $-0 / 21255$ \\
\hline $\mathrm{Na}(4)$ & $249 / 2722$ & $42 / 3615$ & $233 / 0502$ & $237 / 2532$ & $277 / 5131$ & $42 / 3614$ & $28 / 2409$ & $0 / 148827$ & $-0 / 23037$ \\
\hline $\mathrm{K}(5)$ & $252 / 9658$ & $41 / 0209$ & $235 / 9696$ & $242 / 6146$ & $280 / 313$ & $41 / 0209$ & $27 / 3472$ & $0 / 242986$ & $-0 / 15389$ \\
\hline $\mathrm{Na}(6)$ & $244 / 9906$ & $49 / 7986$ & $224 / 6012$ & $232 / 1808$ & $278 / 1896$ & $49 / 7986$ & $33 / 199$ & $0 / 228308$ & $-0 / 13653$ \\
\hline $\mathrm{K}(7)$ & $240 / 4749$ & $48 / 8061$ & $205 / 23$ & $243 / 1825$ & $273 / 0123$ & $-52 / 8674$ & $-35 / 2449$ & $0 / 846358$ & $-0 / 21228$ \\
\hline $\mathrm{Na}(8)$ & $249 / 5723$ & $42 / 756$ & $233 / 032$ & $237 / 6086$ & $278 / 0764$ & $42 / 7561$ & $28 / 5041$ & $0 / 160559$ & $-0 / 23005$ \\
\hline $\mathrm{K}(9)$ & $252 / 5671$ & $41 / 6697$ & $235 / 2352$ & $242 / 1192$ & $280 / 3469$ & $41 / 6697$ & $27 / 7798$ & $0 / 247806$ & $-0 / 15396$ \\
\hline $\mathrm{Na}(10)$ & $248 / 014$ & $52 / 2335$ & $227 / 3997$ & $233 / 8059$ & $282 / 8363$ & $52 / 2335$ & $34 / 8223$ & $0 / 183968$ & $-0 / 13546$ \\
\hline $\mathrm{K}(11)$ & $246 / 5991$ & $50 / 3672$ & $220 / 4212$ & $239 / 1989$ & $280 / 1773$ & $50 / 36725$ & $33 / 5782$ & $0 / 559223$ & $-0 / 22539$ \\
\hline $\mathrm{Na}(12)$ & $246 / 4697$ & $50 / 2919$ & $220 / 063$ & $239 / 3485$ & $279 / 9977$ & $50 / 29195$ & $33 / 528$ & $0 / 575206$ & $-0 / 22578$ \\
\hline $\mathrm{K}(13)$ & $246 / 7869$ & $53 / 1813$ & $219 / 9415$ & $238 / 1781$ & $282 / 2411$ & $53 / 1813$ & $35 / 4542$ & $0 / 514371$ & $-0 / 14319$ \\
\hline $\mathrm{Na}(14)$ & $243 / 2923$ & $50 / 9142$ & $215 / 0571$ & $237 / 5847$ & $277 / 2351$ & $50 / 9142$ & $33 / 9428$ & $0 / 663693$ & $-0 / 14472$
\end{tabular}


https://doi.org/10.33263/BRIAC116.1426014277

\begin{tabular}{|c|c|c|c|c|c|c|c|c|c|}
\hline $\mathrm{K}(15)$ & $251 / 4987$ & $38 / 5457$ & $235 / 6729$ & $241 / 6274$ & $277 / 1958$ & $38 / 54565$ & 25/6971 & $0 / 231719$ & $-0 / 15646$ \\
\hline $\mathrm{Na}(16)$ & $243 / 0848$ & $53 / 6394$ & $217 / 6059$ & $232 / 8042$ & $278 / 8444$ & $53 / 63935$ & $35 / 7596$ & $0 / 425013$ & $-0 / 14256$ \\
\hline $\mathrm{K}(17)$ & $250 / 9925$ & $38 / 7243$ & $235 / 3248$ & $240 / 8441$ & $276 / 8087$ & $38 / 72425$ & $25 / 8162$ & $0 / 213792$ & $-0 / 15681$ \\
\hline $\mathrm{Na}(18)$ & $246 / 2334$ & $55 / 9561$ & $222 / 1987$ & $232 / 964$ & $283 / 5375$ & $55 / 95615$ & $37 / 3041$ & $0 / 288582$ & $-0 / 14131$ \\
\hline $\begin{array}{c}\text { Ranvie } \\
\text { r } \\
\text { myelin- } \\
\text { sheath }\end{array}$ & $\sigma$ Iso & $\sigma$ Aniso & $\sigma_{11}$ & $\sigma_{22}$ & $\sigma 33$ & $\Delta \sigma$ & $\boldsymbol{\delta}$ & $\eta$ & Charge \\
\hline $\mathrm{C}(60)$ & $243 / 8004$ & 50/9617 & $217 / 0702$ & $236 / 5562$ & $277 / 7748$ & 50/9616 & $33 / 9744$ & $0 / 573549$ & $-0 / 09206$ \\
\hline C(59) & $240 / 7655$ & $49 / 2423$ & $213 / 5315$ & $235 / 1712$ & $273 / 5937$ & $49 / 24235$ & $32 / 8282$ & $0 / 65918$ & $-0 / 09332$ \\
\hline $\mathrm{C}(58)$ & $236 / 6804$ & $50 / 2121$ & $198 / 7245$ & $241 / 1615$ & $270 / 1551$ & $-56 / 9338$ & $-37 / 9559$ & $0 / 763876$ & $-0 / 11741$ \\
\hline $\mathrm{C}(57)$ & $247 / 2388$ & $41 / 6956$ & $230 / 4242$ & $236 / 2563$ & $275 / 0359$ & $41 / 69565$ & $27 / 7971$ & 0/20981 & $\begin{array}{l}-0 / 13763 \\
\end{array}$ \\
\hline $\mathrm{C}(56)$ & $248 / 7867$ & $40 / 4803$ & $230 / 9969$ & $239 / 5897$ & $275 / 7736$ & $40 / 4803$ & $26 / 9869$ & $0 / 318406$ & $-0 / 10621$ \\
\hline $\mathrm{C}(55)$ & $240 / 506$ & $50 / 4224$ & $217 / 1651$ & $230 / 2319$ & $274 / 121$ & $50 / 4225$ & $33 / 615$ & $0 / 388719$ & $-0 / 09038$ \\
\hline $\mathrm{C}(54)$ & $236 / 8533$ & $50 / 4837$ & $199 / 5179$ & $240 / 5329$ & $270 / 5091$ & $-56 / 0031$ & $-37 / 3354$ & $0 / 802889$ & $-0 / 11691$ \\
\hline $\mathrm{C}(53)$ & $247 / 4542$ & $41 / 94$ & $230 / 7185$ & $236 / 2299$ & $275 / 4142$ & $41 / 94$ & $27 / 96$ & $0 / 197117$ & $-0 / 13723$ \\
\hline $\mathrm{C}(52)$ & $248 / 542$ & $40 / 9447$ & $230 / 6894$ & $239 / 0981$ & $275 / 8384$ & $40 / 94465$ & $27 / 2964$ & $0 / 308052$ & $-0 / 10611$ \\
\hline $\mathrm{C}(51)$ & $243 / 3123$ & $52 / 4061$ & $220 / 5998$ & $231 / 0874$ & $278 / 2497$ & $52 / 4061$ & $34 / 9374$ & $0 / 300183$ & $-0 / 08908$ \\
\hline $\mathrm{C}(50)$ & $243 / 856$ & $51 / 3227$ & $217 / 0101$ & $236 / 4868$ & $278 / 0712$ & $51 / 32275$ & $34 / 2152$ & $0 / 569241$ & $-0 / 13082$ \\
\hline $\mathrm{C}(49)$ & $243 / 7783$ & $51 / 0232$ & $216 / 7023$ & $236 / 8389$ & $277 / 7938$ & $51 / 0232$ & $34 / 0155$ & $0 / 591983$ & $-0 / 13135$ \\
\hline $\mathrm{C}(48)$ & $242 / 578$ & 54/8494 & $212 / 6928$ & $235 / 8968$ & $279 / 1442$ & 54/8494 & $36 / 5662$ & $0 / 634575$ & $-0 / 09392$ \\
\hline $\mathrm{C}(47)$ & $239 / 4881$ & $52 / 1709$ & $209 / 0274$ & $235 / 1682$ & $274 / 2687$ & $52 / 1709$ & $34 / 7806$ & $0 / 751591$ & $-0 / 09542$ \\
\hline $\mathrm{C}(44)$ & $247 / 9299$ & $41 / 1023$ & $230 / 1798$ & $238 / 2784$ & $275 / 3314$ & $41 / 1023$ & $27 / 4015$ & $0 / 295553$ & $-0 / 10695$ \\
\hline $\mathrm{C}(43)$ & $239 / 1155$ & $54 / 1622$ & $212 / 2042$ & $229 / 9187$ & $275 / 2237$ & $54 / 16225$ & $36 / 1082$ & $0 / 490595$ & $-0 / 09265$ \\
\hline $\mathrm{C}(40)$ & $247 / 6403$ & $41 / 3649$ & $230 / 0628$ & $237 / 6411$ & $275 / 2169$ & $41 / 36495$ & $27 / 5766$ & $0 / 274809$ & $-0 / 10698$ \\
\hline $\mathrm{C}(39)$ & $241 / 9989$ & $57 / 1552$ & $215 / 7641$ & $230 / 1301$ & $280 / 1023$ & $57 / 1552$ & $38 / 1034$ & $0 / 377027$ & $-0 / 09119$ \\
\hline
\end{tabular}

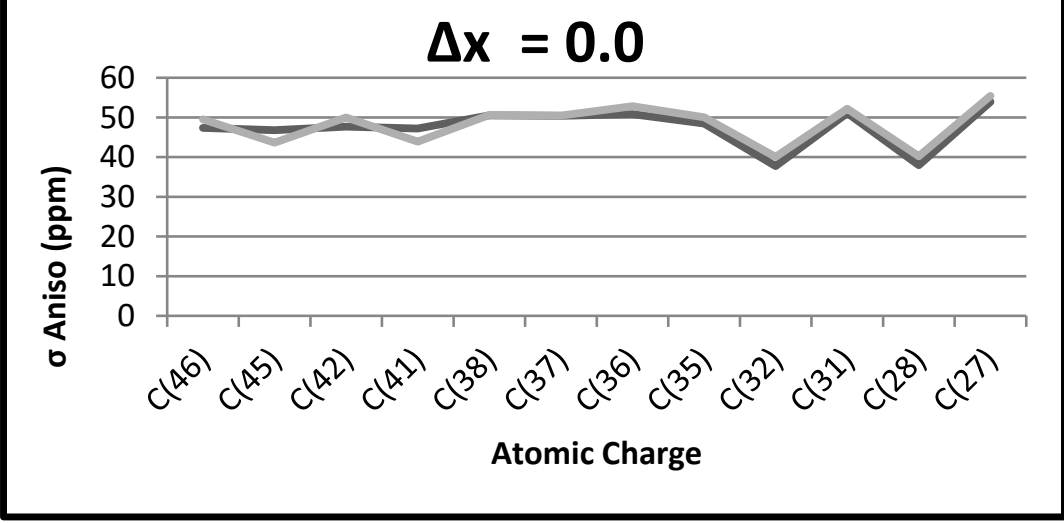

Figure 7. Aniso versus atomic charge.

Table 5. NMR parameters of sodium/potassium systems in both isolated and Ranvier myelin sheath media.

\begin{tabular}{|c|c|c|c|c|c|c|c|c|c|}
\hline Atom & $\sigma$ Iso & $\sigma$ Aniso & $\sigma_{11}$ & $\sigma_{22}$ & $\sigma_{33}$ & $\Delta \sigma$ & $\boldsymbol{\delta}$ & $\eta$ & Charge \\
\hline $\mathrm{K}(18)$ & $248 / 2586$ & $49 / 1662$ & $225 / 5372$ & $238 / 2024$ & $281 / 036$ & $49 / 1662$ & $32 / 7774$ & $0 / 3864$ & $-0 / 16362$ \\
\hline $\mathrm{Na}(19)$ & $244 / 6769$ & $46 / 728$ & $221 / 527$ & $236 / 6749$ & $275 / 8289$ & $46 / 72795$ & $31 / 152$ & $0 / 486258$ & $-0 / 16452$ \\
\hline $\mathrm{K}(20)$ & $240 / 0278$ & $49 / 2857$ & $204 / 4162$ & $242 / 7823$ & $272 / 8849$ & $-53 / 4174$ & $-35 / 6116$ & $0 / 845303$ & $-0 / 20896$ \\
\hline $\mathrm{Na}(21)$ & $249 / 1637$ & $42 / 8909$ & $232 / 7277$ & $237 / 0059$ & $277 / 7577$ & $42 / 8909$ & $28 / 594$ & $0 / 149619$ & $-0 / 22804$ \\
\hline $\mathrm{K}(22)$ & $252 / 165$ & $39 / 3522$ & $235 / 587$ & $242 / 5081$ & $278 / 3998$ & $39 / 35225$ & $26 / 2348$ & $0 / 263814$ & $-0 / 17914$ \\
\hline $\mathrm{Na}(23)$ & $244 / 3277$ & $49 / 1613$ & $224 / 438$ & $231 / 4433$ & $277 / 1019$ & $49 / 16125$ & $32 / 7742$ & $0 / 213744$ & $-0 / 1618$ \\
\hline $\mathrm{K}(24)$ & $240 / 1326$ & $49 / 5135$ & $204 / 9463$ & $242 / 3099$ & $273 / 1417$ & $-52 / 7795$ & $-35 / 1863$ & $0 / 876244$ & $-0 / 20864$ \\
\hline $\mathrm{Na}(25)$ & $249 / 4846$ & $43 / 3909$ & $232 / 6855$ & $237 / 3565$ & $278 / 4119$ & $43 / 3909$ & $28 / 9273$ & $0 / 161474$ & $-0 / 2277$ \\
\hline $\mathrm{K}(26)$ & $251 / 662$ & $39 / 8836$ & $234 / 8564$ & $241 / 8786$ & $278 / 2511$ & $39 / 8836$ & $26 / 5891$ & $0 / 264101$ & $-0 / 17915$ \\
\hline $\mathrm{Na}(27)$ & $247 / 5538$ & $52 / 1497$ & $226 / 8105$ & $233 / 5306$ & $282 / 3203$ & $52 / 14975$ & $34 / 7665$ & $0 / 193292$ & $-0 / 16093$ \\
\hline $\mathrm{Na}(28)$ & $246 / 36$ & $50 / 4753$ & $220 / 6801$ & $238 / 3897$ & $280 / 0101$ & $50 / 4752$ & $33 / 6501$ & $0 / 526287$ & $-0 / 22212$ \\
\hline $\mathrm{K}(29)$ & $246 / 2498$ & $50 / 5152$ & $220 / 2201$ & $238 / 6026$ & $279 / 9266$ & $50 / 51525$ & $33 / 6768$ & $0 / 545851$ & $-0 / 22251$ \\
\hline $\mathrm{Na}(30)$ & $246 / 7316$ & $54 / 5191$ & $218 / 7956$ & $238 / 3215$ & $283 / 0777$ & $54 / 51915$ & $36 / 3461$ & $0 / 537221$ & $-0 / 11828$ \\
\hline $\mathrm{K}(31)$ & $243 / 3489$ & $52 / 2115$ & $214 / 0415$ & $237 / 8486$ & $278 / 1566$ & $52 / 21155$ & $34 / 8077$ & $0 / 683961$ & $-0 / 11981$ \\
\hline $\mathrm{Na}(32)$ & $251 / 5103$ & $39 / 9216$ & $235 / 0401$ & $241 / 3662$ & $278 / 1247$ & $39 / 92155$ & $26 / 6144$ & $0 / 237695$ & $-0 / 13114$ \\
\hline $\mathrm{K}(33)$ & $243 / 0058$ & $54 / 6863$ & $216 / 681$ & $232 / 8731$ & $279 / 4634$ & $54 / 68635$ & $36 / 4576$ & $0 / 444135$ & $-0 / 11754$ \\
\hline
\end{tabular}

https://biointerfaceresearch.com/ 


\begin{tabular}{c|c|c|l|l|l|l|l|l|c}
\hline $\mathrm{Na}(34)$ & $251 / 0113$ & $39 / 9811$ & $234 / 6761$ & $240 / 6924$ & $277 / 6653$ & $39 / 98105$ & $26 / 654$ & $0 / 225718$ & $-0 / 13146$ \\
\hline $\mathrm{K}(35)$ & $246 / 0624$ & $57 / 2716$ & $221 / 043$ & $232 / 9008$ & $284 / 2435$ & $57 / 2716$ & $38 / 1811$ & $0 / 310567$ & $-0 / 11628$ \\
\hline Atom & $\boldsymbol{\sigma}$ Iso & $\boldsymbol{\sigma A n i s o}$ & $\boldsymbol{\sigma} \mathbf{1 1}$ & $\boldsymbol{\sigma}_{\mathbf{2 2}}$ & $\boldsymbol{\sigma} \mathbf{3 3}$ & $\Delta \boldsymbol{\sigma}$ & $\boldsymbol{\delta}$ & $\boldsymbol{\eta}$ & Charge \\
\hline $\mathrm{C}(48)$ & $243 / 6162$ & $49 / 4177$ & $218 / 9691$ & $235 / 3183$ & $276 / 5613$ & $49 / 4176$ & $32 / 9451$ & $0 / 496256$ & $-0 / 10345$ \\
\hline $\mathrm{C}(47)$ & $240 / 4753$ & $47 / 7269$ & $215 / 033$ & $234 / 0997$ & $272 / 2933$ & $47 / 72695$ & $31 / 818$ & $0 / 599243$ & $-0 / 10453$ \\
\hline $\mathrm{C}(46)$ & $236 / 5505$ & $50 / 435$ & $198 / 5391$ & $240 / 9386$ & $270 / 1738$ & $-57 / 0171$ & $-38 / 0114$ & $0 / 769117$ & $-0 / 11581$ \\
\hline $\mathrm{C}(45)$ & $247 / 2324$ & $42 / 5416$ & $230 / 0531$ & $236 / 0506$ & $275 / 5935$ & $42 / 54165$ & $28 / 3611$ & $0 / 211469$ & $-0 / 13651$ \\
\hline $\mathrm{C}(44)$ & $248 / 2318$ & $38 / 3387$ & $232 / 7674$ & $238 / 137$ & $273 / 7909$ & $38 / 3387$ & $25 / 5591$ & $0 / 210086$ & $-0 / 11754$ \\
\hline $\mathrm{C}(43)$ & $240 / 2388$ & $49 / 3871$ & $218 / 5999$ & $228 / 953$ & $273 / 1635$ & $49 / 38705$ & $32 / 9247$ & $0 / 314448$ & $-0 / 10156$ \\
\hline $\mathrm{C}(42)$ & $236 / 7327$ & $50 / 8596$ & $199 / 2785$ & $240 / 2804$ & $270 / 6391$ & $-56 / 1813$ & $-37 / 4542$ & $0 / 810555$ & $-0 / 1152$ \\
\hline $\mathrm{C}(41)$ & $247 / 4772$ & $42 / 8579$ & $230 / 358$ & $236 / 0245$ & $276 / 0492$ & $42 / 85795$ & $28 / 572$ & $0 / 198324$ & $-0 / 13608$ \\
\hline $\mathrm{C}(40)$ & $247 / 9221$ & $38 / 6917$ & $232 / 3768$ & $237 / 673$ & $273 / 7166$ & $38 / 6917$ & $25 / 7945$ & $0 / 205323$ & $-0 / 11739$ \\
\hline $\mathrm{C}(39)$ & $243 / 1724$ & $51 / 5872$ & $222 / 236$ & $229 / 7172$ & $277 / 5638$ & $51 / 5872$ & $34 / 3914$ & $0 / 217531$ & $-0 / 10044$ \\
\hline $\mathrm{C}(38)$ & $243 / 7851$ & $51 / 8899$ & $216 / 7568$ & $236 / 2202$ & $278 / 3784$ & $51 / 8899$ & $34 / 5933$ & $0 / 562635$ & $-0 / 12925$
\end{tabular}

In short distances of the region around the molecular centers, the asymmetric parameter $(\eta)$, and the skew (к), exhibited Gaussian distribution based on their fluctuation behavior, which is dependent on their distances from the center of the molecular rings. These lines' slopes are changed, and among the levels of various distances for isolated sodium/potassium systems and sodium/potassium systems @ Ranvier myelin sheath media (Figures 7,8). The isotropy during the replacing of sodium/potassium @ Ranvier myelin sheath is positive, indicating negative values for sodium/potassium pumping, but the slopes are decreased from the replacing from 0.1 to center. We have shown the slopes of voltages curves versus distances to the center of the sodium/potassium systems @ Ranvier myelin sheath media are decreased by decreasing the distances gradually, which indicates suitable pumping, and on the other hand, these slopes are increased by increasing the distance, emphasizing a special electronic structure in sodium/potassium systems @ Ranvier myelin. [66-100].

In the S-NICS method via statistical calculations, the shielding space's best point around the center of symmetric or non-symmetric aromatic molecules can be evaluated as an aromaticity criterion. In this method, the expectation of the $\left(\eta^{*}\right)$ and $\left(\kappa^{*}\right)$ have been calculated as the Gaussian curve functions versus one, two, or three-dimensional distances around the center (Figure 9).

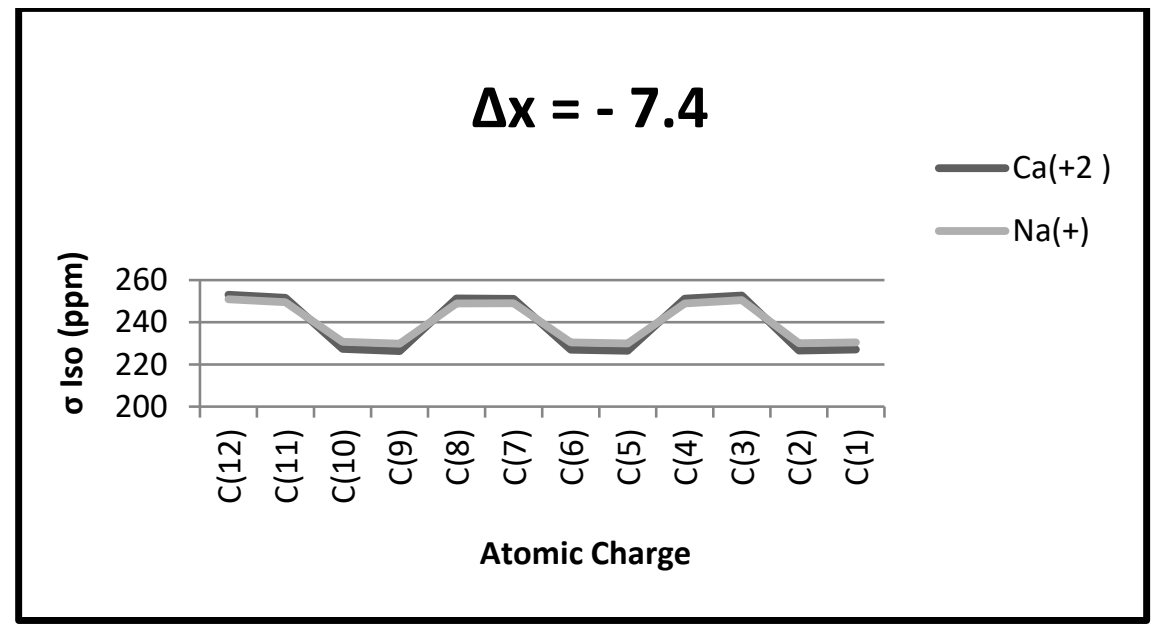

Figure 8. Iso versus atomic charge. 


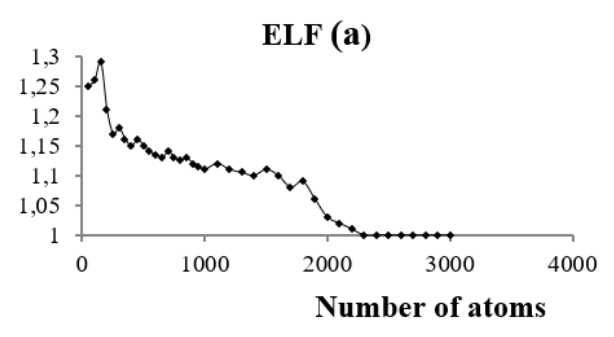

(c)

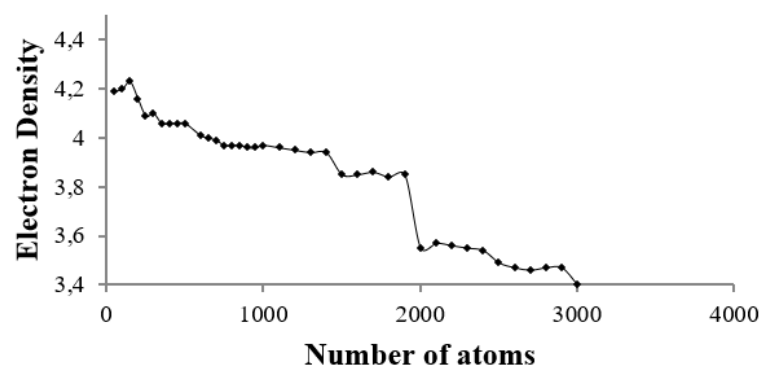

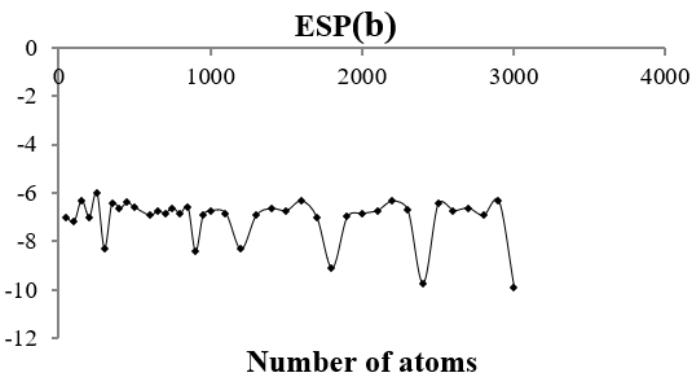

(d)

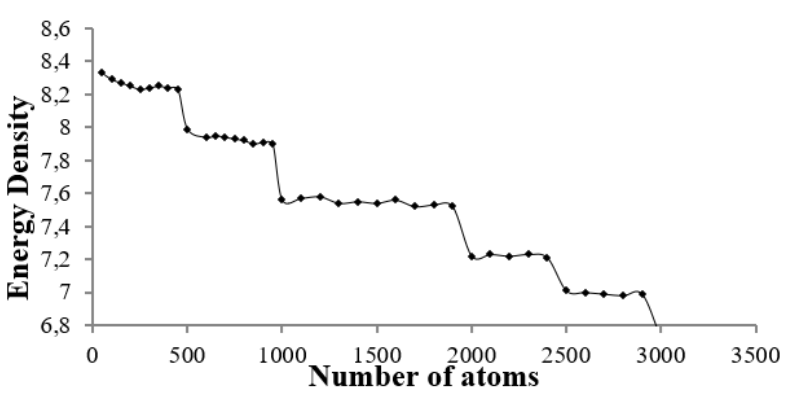

Figure 9. The electron density profiles for $60 \mathrm{GalC} / \mathrm{DPPC}$.

\section{Conclusions}

When a protein is coiled, the magnetic field produced by current flow expands across adjacent coil rings. These effects do not occur in the static conditions in GalC/DPPC, GalC/DMPC myelin's membranes due to the steady currents. These impacts only appear and arise in the variable capacitors when the current experiences are changing their value. When currents flow quickly, the magnetic field also collapses quickly. It can generate high induced electro-motoric forces (emf), which at times can be several times the original amounts of the source's voltages. Higher induced voltages might be created in inductive circuits by increasing the currents' rate of changes and increasing the number of coils in myelin's helical proteins. Myelin's membrane proteins as electrical inductors might enable the membrane cell to produce very high electrical voltages such as Bio-Nano-Antenna transiently.

\section{Funding}

This research received no external funding.

\section{Acknowledgments}

This research has no acknowledgment.

\section{Conflicts of Interest}

The authors declare no conflict of interest.

\section{References}

1. Keizer, J.; Smith, G.D.; Ponce-Dawson, S.; Pearson, J.E. Saltatory Propagation of Ca2+ Waves by Ca2+ Sparks. Biophys. J. 1998, 75, 595-600, https://doi.org/10.1016/S0006-3495(98)77550-2.

2. Boullerne, A.I. The history of myelin. Exp. Neurol. 2016, 283, 431-445, https://doi.org/10.1016/j.expneurol.2016.06.005. 
3. Salzer, J.L. Clustering sodium channels at the node of Ranvier: close encounters of the axon-glia kind. Neuron 1997, 18, 843-846, https://doi.org/10.1016/S0896-6273(00)80323-2.

4. Monajjemi, M. Cell membrane causes the lipid bilayers to behave as variable capacitors: A resonance with self-induction of helical proteins. Biophys. Chem. 2015, 207, 114-127.

5. Swire, M. Seeing is believing: Myelin dynamics in the adult CNS. Neuron 2018, 98, 684686, https://doi.org/10.1016/j.neuron.2018.05.005.

6. Hill, R.A.; Li, A.M.; Grutzendler, J. Lifelong cortical myelin plasticity and age-related degeneration in the live mammalian brain. Nat. Neurosci. 2018, 21, 683-695, https://doi.org/10.1038/s41593-018-0120-6.

7. Hughes, E.G.; Orthmann-Murphy, J.L.; Langseth, A.J.; Bergles, D.E. Myelin remodeling through experiencedependent oligodendrogenesis in the adult somatosensory cortex. Nat. Neurosci. 2018, 21, 696-706, https://doi.org/10.1038/s41593-018-0121-5.

8. Hartline, D.K. What is myelin? Neuron Glia Biol. 2008, 4, 153-163, https://doi.org/10.1017/S1740925X09990263.

9. Salzer, J.L.; Zalc, B. Myelination. Curr. Biol. 2016, 26, R971-R975, https://doi.org/10.1016/j.cub.2016.07.074.

10. Steinman, L. Multiple sclerosis: a coordinated immunological attack against myelin in the central nervous system. Cell 1996, 85, 299-302, https://doi.org/10.1016/S0092-8674(00)81107-1.

11. Greer, J.M.; Lees, M.B. Myelin proteolipid protein-the first 50 years. The International Journal of Biochemistry \& Cell Biology 2002, 34, 211-215, https://doi.org/10.1016/S1357-2725(01)00136-4.

12. Raine, C.S. Characteristics of Neuroglia. In Basic Neurochemistry: Molecular, Cellular and Medical Aspectsi, (6th ed.). Philadelphia: Lippincott-Raven; 1999.

13. Kaplan, M.R.; Cho, M.-H.; Ullian, E.M.; Isom, L.L.; Levinson, S.R.; Barres, B.A. Differential control of clustering of the sodium channels Nav1. 2 and Nav1. 6 at developing CNS nodes of Ranvier. Neuron 2001, 30, 105-119, https://doi.org/10.1016/S0896-6273(01)00266-5.

14. Tasaki, I.; Kusano, K.; Byrne, P.M. Rapid mechanical and thermal changes in the garfish olfactory nerve associated with a propagated impulse. Biophys. J. 1989, 55, 1033-1040, , https://doi.org/10.1016/S00063495(89)82902-9.

15. Iwasa, K.; Tasaki, I.; Gibbons, R.C. Swelling of nerve fibers associated with action potentials. Science 1980, 210, 338-339, https://doi.org/10.1126/science.7423196.

16. Kobatake, Y.; Tasaki, I.; Watanabe, A. Phase transition in membrane with reference to nerve excitation. Adv. Biophys. 1971, 2, 1-31.

17. Hodgkin, A.L.; Katz, B. The effect of sodium ions on the electrical activity of giant axon of the squid. The Journal of physiology 1949, 108, 37-77, https://doi.org/10.1113/jphysiol.1949.sp004310.

18. Hodgkin, A.L.; Huxley, A.F. A quantitative description of membrane current and its application to conduction and excitation in nerve. The Journal of physiology 1952, 117, 500-544, https://doi.org/10.1113/jphysiol.1952.sp004764.

19. Hodgkin, A.L.; Huxley, A.F. Currents carried by sodium and potassium ions through the membrane of the giant axon of Loligo. The Journal of physiology 1952, 116, 449-472, https://doi.org/10.1113/jphysiol.1952.sp004717.

20. Häusser, M. The Hodgkin-Huxley theory of the action potential. Nat. Neurosci. 2000, 3, 1165-1165, https://doi.org/10.1038/81426.

21. FitzHugh, R. Impulses and Physiological States in Theoretical Models of Nerve Membrane. Biophys. J. 1961, 1, 445-466, https://doi.org/10.1016/S0006-3495(61)86902-6.

22. Nagumo, J.; Arimoto, S.; Yoshizawa, S. An Active Pulse Transmission Line Simulating Nerve Axon. Proc. IRE 1962, 50, 2061-2070, https://doi.org/10.1109/JRPROC.1962.288235.

23. Hindmarsh, J.L.; Rose, R.M.; Huxley, A.F. A model of neuronal bursting using three coupled first order differential equations. Proceedings of the Royal Society of London. Series B. Biological Sciences 1984, 221, 87-102, https://doi.org/10.1098/rspb.1984.0024.

24. Rajagopal, K. A generalized model for the nerve impulse propagation. Phys. Lett. A 1983, 99, 261-264, https://doi.org/10.1016/0375-9601(83)90923-4.

25. Bologa-Sandru, L.; Zalc, B.; Herschkowitz, N.; Baumann, N. Oligodendrocytes of jimpy mice express galactosylceramide: an immunofluorescence study on brain sections and dissociated brain cell cultures. Brain Res. 1981, 225, 425-430, https://doi.org/10.1016/0006-8993(81)90848-9.

26. Pascher, I.; Sundell, S. Molecular arrangements in sphingolipids. The crystal structure of cerebroside. Chem. Phys. Lipids 1977, 20, 175-191, https://doi.org/10.1016/0009-3084(77)90033-0. 
27. Abrahamsson, S.; Pascher, I.; Larsson, K.; Karlsson, K.-A. Molecular arrangements in glycosphingolipids. Chem. Phys. Lipids 1972, 8, 152-179.

28. Correa-Freire, M.C.; Freire, E.; Barenholz, Y.; Biltonen, R.L.; Thompson, T.E. Thermotropic behavior of monoglucocerebroside--dipalmitoylphosphatidylcholine multilamellar liposomes. Biochemistry 1979, 18, 442-445, https://doi.org/10.1021/bi00570a008.

29. Linington, C.; Rumsby, M.G. Galactosyl ceramides of the myelin sheath: thermal studies. Neurochem. Int. 1981, 3, 211-218, https://doi.org/10.1016/0197-0186(81)90003-6.

30. Bunow, M.R.; Levin, I.W. Molecular conformations of cerebrosides in bilayers determined by Raman spectroscopy. Biophys. J. 1980, 32, 1007-1021, https://doi.org/10.1016/s0006-3495(80)85032-6.

31. Koch, C. Biophysics of computation: Information processing in single neurons. New York: Oxford Univ. Press.1999,

32. Major, G.; Evans, J.D.; Jack, J.J. Solutions for transients in arbitrarily branching cables: I. Voltage recording with a somatic shunt. Biophys. J. 1993, 65, 423-449, https://doi.org/10.1016/S0006-3495(93)81037-3.

33. Major, G.; Evans, J.D.; Jack, J.J. Solutions for transients in arbitrarily branching cables: II. Voltage clamp theory. Biophys. J. 1993, 65, 450-468, https://doi.org/10.1016/s0006-3495(93)81038-5.

34. Holmes, W.R.; Segev, I.; Rall, W. Interpretation of time constant and electrotonic length estimates in multicylinder or branched neuronal structures. J. Neurophysiol. 1992, 68, 1401-1420, https://doi.org/10.1152/jn.1992.68.4.1401.

35. Klein, D.L.; Roth, R.; Lim, A.K.L.; Alivisatos, A.P.; McEuen, P.L. A single-electron transistor made from a cadmium selenide nanocrystal. Nature 1997, 389, 699-701, https://doi.org/10.1038/39535.

36. Mollaamin, F.; Monajjemi, M. DFT outlook of solvent effect on function of nano bioorganic drugs. Phys. Chem. Liq. 2012, 50, 596-604, https://doi.org/10.1080/00319104.2011.646444.

37. Mollaamin, F.; Gharibe, S.; Monajjemi, M. Synthesis of various nano and micro ZnSe morphologies by using hydrothermal method. International Journal of the Physical Sciences 2011, 6, 1496-1500.

38. Ardalan, T.; Ardalan, P.; Monajjemi, M. Nano Theoretical Study of a C16 Cluster as a Novel Material for Vitamin C Carrier. Fullerenes, Nanotubes and Carbon Nanostructures 2014, 22, 687-708, https://doi.org/10.1080/1536383X.2012.717561.

39. Mahdavian, L.; Monajjemi, M.; Mangkorntong, N. Sensor Response to Alcohol and Chemical Mechanism of Carbon Nanotube Gas Sensors. Fullerenes, Nanotubes and Carbon Nanostructures 2009, 17, 484-495, https://doi.org/10.1080/15363830903130044.

40. Monajjemi, M.; Najafpour, J. Charge Density Discrepancy Between NBO and QTAIM in Single-wall Armchair Carbon Nanotubes. Fullerenes, Nanotubes and Carbon Nanostructures 2014, 22, 575-594, https://doi.org/10.1080/1536383X.2012.702161.

41. Monajjemi, M.; Seyed Hosseini, M. Non Bonded Interaction of B16N16 Nano Ring with Copper Cations in Point of Crystal Fields. Journal of Computational and Theoretical Nanoscience 2013, 10, 2473-2477.

42. Monajjemi, M.; Mahdavian, L.; Mollaamin, F. Characterization of nanocrystalline silicon germanium film and nanotube in adsorption gas by Monte Carlo and Langevin dynamic simulation. Bull. Chem. Soc. Ethiop. 2008, 22, http://dx.doi.org/10.4314/bcse.v22i2.61299.

43. Lee, V.S.; Nimmanpipug, P.; Mollaamin, F.; Kungwan, N.; Thanasanvorakun, S.; Monajjemi, M. Investigation of single wall carbon nanotubes electrical properties and normal mode analysis: Dielectric effects. Russian Journal of Physical Chemistry A 2009, 83, 2288-2296, https://doi.org/10.1134/S0036024409130184.

44. Mollaamin, F.; Najafpour, J.; Ghadami, S.; Akrami, M.S.; Monajjemi, M. The electromagnetic feature of B $\mathrm{N} \mathrm{H}(\mathrm{x}=0,4,8,12,16$, and 20) nano rings:Quantum theory of atoms in molecules/NMR approach. Journal of Computational and Theoretical Nanoscience 2014, 11, 1290-1298.

45. Monajjemi, M.; Mahdavian, L.; Mollaamin, F.; Honarparvar, B. Thermodynamic Investigation of Enol $\leftrightarrow$ Keto Tautomerism for Alcohol Sensors Based on Carbon Nanotubes as Chemical Sensors. Fullerenes, Nanotubes and Carbon Nanostructures 2010, 18, 45-55, https://doi.org/10.1080/15363830903291564.

46. Monajjemi, M.; Ghiasi, R.; Sadjadi, M.A.S. Metal-stabilized rare tautomers: N4 metalated cytosine (M $=\mathrm{Li}+$, $\mathrm{Na}+, \mathrm{K}+, \mathrm{Rb}+$ and $\mathrm{Cs}+)$, theoretical views. Appl. Organomet. Chem. 2003, 17, 635-640, https://doi.org/10.1002/aoc.469.

47. Ilkhani, A.R.; Monajjemi, M. The pseudo Jahn-Teller effect of puckering in pentatomic unsaturated rings C4AE5, A=N, P, As, E=H, F, Cl. Computational and Theoretical Chemistry 2015, 1074, 19-25, https://doi.org/10.1016/j.comptc.2015.10.006. 
48. Monajjemi, M. Non-covalent attraction of B $2 \mathrm{~N}(-, 0)$ and repulsion of $\mathrm{B} 2 \mathrm{~N}(+)$ in the $\mathrm{B} n \mathrm{~N} \mathrm{n}$ ring: a quantum rotatory due to an external field. Theor. Chem. Acc. 2015, 134, 77, https://doi.org/10.1007/s00214015-1668-9.

49. Monajjemi, M.; Naderi, F.; Mollaamin, F.; Khaleghian, M. Drug design outlook by calculation of second virial coefficient as a nano study. Journal of the mexican chemical society 2012, 56, 207-211.

50. Monajjemi, M.; Bagheri, S.; Moosavi, M.S.; Moradiyeh, N.; Zakeri, M.; Attarikhasraghi, N.; Saghayimarouf, N.; Niyatzadeh, G.; Shekarkhand, M.; Khalilimofrad, M.S.; Ahmadin, H.; Ahadi, M. Symmetry Breaking of B2N(-, 0, +): An Aspect of the Electric Potential and Atomic Charges. Molecules 2015, 20, https://doi.org/10.3390/molecules201219769.

51. Monajjemi, M.; Mohammadian, N.T. S-NICS: An Aromaticity Criterion for Nano Molecules. Journal of Computational and Theoretical Nanoscience 2015, 12, 4895-4914, https://doi.org/10.1166/jctn.2015.4458.

52. Monajjemi, M.; Ketabi, S.; Hashemian Zadeh, M.; Amiri, A. Simulation of DNA bases in water: Comparison of the Monte Carlo algorithm with molecular mechanics force fields. Biochemistry (Moscow) 2006, 71, S1S8, https://doi.org/10.1134/S0006297906130013.

53. Monajjemi, M.; Lee, V.S.; Khaleghian, M.; Honarparvar, B.; Mollaamin, F. Theoretical Description of Electromagnetic Nonbonded Interactions of Radical, Cationic, and Anionic NH2BHNBHNH2 Inside of the B18N18 Nanoring. The Journal of Physical Chemistry C 2010, 114, 15315-15330, http://dx.doi.org/10.1021/jp104274z.

54. Monajjemi, M.; Boggs, J.E. A New Generation of BnNn Rings as a Supplement to Boron Nitride Tubes and Cages. The Journal of Physical Chemistry A 2013, 117, 1670-1684, http://dx.doi.org/10.1021/jp312073q.

55. Monajjemi, M. Non bonded interaction between $\mathrm{BnNn}$ (stator) and $\mathrm{BN}(-, 0,+) \mathrm{B}$ (rotor) systems: A quantum rotation in IR region. Chem. Phys. 2013, 425, 29-45, https://doi.org/10.1016/j.chemphys.2013.07.014.

56. Monajjemi, M.; Wayne, R.; Boggs, J.E. NMR contour maps as a new parameter of carboxyl's OH groups in amino acids recognition: A reason of tRNA-amino acid conjugation. Chem. Phys. 2014, 433, 1-11, https://doi.org/10.1016/j.chemphys.2014.01.017.

57. Monajjemi, M. Quantum investigation of non-bonded interaction between the B $15 \mathrm{~N} 15$ ring and $\mathrm{BH} 2 \mathrm{NBH}$ 2 (radical, cation, anion) systems: A nano molecularmotor. Struct. Chem. 2011, http://dx.doi.org/10.1007/s11224-011-9895.

58. Monajjemi, M. Metal-doped graphene layers composed with boron nitride-graphene as an insulator: a nanocapacitor. J. Mol. Model. 2014, 20, 2507, https://doi.org/10.1007/s00894-014-2507-y.

59. Monajjemi, M. Graphene/(h-BN) n/X-doped graphene as anode material in lithium ion batteries $(\mathrm{X}=\mathrm{Li}, \mathrm{Be}$, $\mathrm{B}$ and N). Macedonian Journal of Chemistry and Chemical Engineering 2017, 36, 101-118, http://dx.doi.org/10.20450/mjcce.2017.1134.

60. Monajjemi, M. Study of CD5+ Ions and Deuterated Variants $(\mathrm{CHxD}(5-\mathrm{x})+)$ : An Artefactual Rotation. Russian Journal of Physical Chemistry A 2018, 92, 2215-2226.

61. Monajjemi, M. Liquid-phase exfoliation (LPE) of graphite towards graphene: An ab initio study. J. Mol. Liq. 2017, 230, 461-472.

62. Jalilian, H.; Monajjemi, M. Capacitor simulation including of X-doped graphene (X= Li, Be, B) as two electrodes and (h-BN) $\mathrm{m}(\mathrm{m}=1-4)$ as the insulator. Jpn. J. Appl. Phys. 2015, 54, 085101.

63. Pham, T.; Monajjemi, M.; Dang, C. Fabrication of lithium-ion batteries based on various LiNi1-xCoxO2 cathode materials. International Journal of Nanotechnology 2018, 15, 925, https://doi.org/10.1504/IJNT.2018.099932.

64. Monajjemi, M.; Dang, C.M.; Dang, D.M.T.; Alihosseini, A.; Mollaamin, F. Designing BN sheets of XG//(h$\mathrm{BN}) \mathrm{n} / \mathrm{XG}(\mathrm{X}=\mathrm{B}, \mathrm{N})$ and $\mathrm{GO} / \mathrm{h}-\mathrm{BN} / \mathrm{GO}$ structures for based anodes material to improve the performance of lithium-ion batteries. International Journal of Nanotechnology 2018, 15, 819-844.

65. Le, C.M.T.; Fribourg-Blanc, E.; Monajjemi, M.; Dang, C.M. Theoretical and experimental simulation of inkjet printing process: investigation of physical parameters of a droplet. International Journal of Nanotechnology 2018, 15, 845-857.

66. Kohn W., Sham L.J., Self-Consistent Equations Including Exchange and Correlation Effects, Phys. Rev., 140 A, $1133-$ $1138,1965$.

67. Perdew J.P., Burke K., Ernzerhof, Generalized Gradient Approximation Made Simple, Phys. Rev. Lett 1996, 77, 38653868.

68. Besler, B.H.; Merz Jr, K.M.; Kollman, P.A. Atomic charges derived from semi-empirical methods. J. Comput. Chem. 1990, 11, 431-439, https://doi.org/10.1002/jcc.540110404. 
69. Lu, T.; Chen, F. Multiwfn: A multifunctional wavefunction analyzer. J. Comput. Chem. 2012, 33, 580-592, https://doi.org/10.1002/jcc.22885.

70. Jacak, J.E.; Jacak, W.A. New wave-type mechanism of saltatory conduction in myelinated axons and microsaltatory conduction in C fibres. Eur. Biophys. J. 2020, 49, 343-360, https://doi.org/10.1007/s00249-02001442-z.

71. Song, X.; Wang, H.; Chen, Y.; Lai, Y.-C. Emergence of an optimal temperature in action-potential propagation through myelinated axons. Physical Review E 2019, 100, 032416, https://doi.org/10.1103/PhysRevE.100.032416.

72. Jacak, W.A. Nonradiative Energy Losses of Plasmon-Polariton in a Metallic Nano-chain Deposited on a Semiconductor Substrate. Plasmonics 2019, 14, 465-483, https://doi.org/10.1007/s11468-018-0825-0.

73. Baul, U.; Chakraborty, D.; Mugnai, M.L.; Straub, J.E.; Thirumalai, D. Sequence Effects on Size, Shape, and Structural Heterogeneity in Intrinsically Disordered Proteins. The Journal of Physical Chemistry B 2019, 123, 3462-3474, https://doi.org/10.1021/acs.jpcb.9b02575.

74. Wallace, B.A. The role of circular dichroism spectroscopy in the era of integrative structural biology. Curr. Opin. Struct. Biol. 2019, 58, 191-196, https://doi.org/10.1016/j.sbi.2019.04.001.

75. Datta, S.; Kataria, S.; Govindarajan, R. A Case Report on Charcot-Marie-Tooth Disease with a Novel Periaxin Gene Mutation. Cureus 2019, 11.

76. Lin, W.; Stone, S. Unfolded protein response in myelin disorders. Neural regeneration research 2020, 15 , 636.

77. Pancsa, R.; Schad, E.; Tantos, A.; Tompa, P. Emergent functions of proteins in non-stoichiometric supramolecular assemblies. Biochimica et biophysica acta. Proteins and proteomics 2019, 1867, 970-979, https://doi.org/10.1016/j.bbapap.2019.02.007.

78. Raasakka, A.; Linxweiler, H.; Brophy, P.J.; Sherman, D.L.; Kursula, P. Direct Binding of the Flexible CTerminal Segment of Periaxin to $\beta 4$ Integrin Suggests a Molecular Basis for CMT4F. Front. Mol. Neurosci. 2019, 12, 84 .

79. Guo, T.; Zhang, L.; Xiao, H.; Yang, Y.; Shi, Y. Ezrin interacts with L-periaxin by the "head to head and tail to tail" mode and influences the location of L-periaxin in Schwann cell RSC96. Biochimica et biophysica acta. General subjects 2020, 1864, 129520, https://doi.org/10.1016/j.bbagen.2020.129520.

80. Raasakka, A.; Ruskamo, S.; Barker, R.; Krokengen, O.C.; Vatne, G.H.; Kristiansen, C.K.; Hallin, E.I.; Skoda, M.W.A.; Bergmann, U.; Wacklin-Knecht, H.; Jones, N.C.; Hoffmann, S.V.; Kursula, P. Neuropathy-related mutations alter the membrane binding properties of the human myelin protein $\mathrm{P} 0$ cytoplasmic tail. PLoS One 2019, 14, e0216833, https://doi.org/10.1371/journal.pone.0216833.

81. Raasakka, A.; Ruskamo, S.; Kowal, J.; Han, H.; Baumann, A.; Myllykoski, M.; Fasano, A.; Rossano, R.; Riccio, P.; Bürck, J.; Ulrich, A.S.; Stahlberg, H.; Kursula, P. Molecular structure and function of myelin protein P0 in membrane stacking. Sci. Rep. 2019, 9, 642, https://doi.org/10.1038/s41598-018-37009-4.

82. Raasakka, A.; Jones, N.C.; Hoffmann, S.V.; Kursula, P. Ionic strength and calcium regulate membrane interactions of myelin basic protein and the cytoplasmic domain of myelin protein zero. Biochem. Biophys. Res. Commun. 2019, 511, 7-12, https://doi.org/10.1016/j.bbrc.2019.02.025.

83. Dubessy, A.L.; Mazuir, E.; Rappeneau, Q.; Ou, S.; Abi Ghanem, C.; Piquand, K.; Aigrot, M.S.; Thetiot, M.; Desmazieres, A.; Chan, E.; et al. Role of a contactin multi-molecular complex secreted by oligodendrocytes in nodal protein clustering in the cns. Glia 2019, 67, 2248-2263.

84. Benamer, N.; Vidal, M.; Angulo, M.C. The cerebral cortex is a substrate of multiple interactions between gabaergic interneurons and oligodendrocyte lineage cells. Neurosci. Lett. 2020, 715, 134615.

85. Maiuolo, J.; Macrì, R.; Bava, I.; Gliozzi, M.; Musolino, V.; Nucera, S.; Carresi, C.; Scicchitano, M.; Bosco, F.; Scarano, F.; et al. Myelin Disturbances Produced by Sub-Toxic Concentration of Heavy Metals: The Role of Oligodendrocyte Dysfunction. Int. J. Mol. Sci. 2019, $20,4554$.

86. Thomason, M.E.; Hect, J.L.; Rauh, V.A.; Trentacosta, C.; Wheelock, A.T.; Eggebrecht, A.T.; EspinozaHeredia, C.; Burt, A. Prenatal lead exposure impacts cross-hemispheric and long-range connectivity in the human fetal brain. NeuroImage 2019, 191, 186-192

87. Pancsa, R.; Schad, E.; Tantos, A.; Tompa, P. Emergent functions of proteins in non-stoichiometric supramolecular assemblies. Biochim. Biophys. Acta Proteins Proteom. 2019, 1867, 970-979.

88. Maiolino, M.; O’Neill, N.; Lariccia, V.; Amoroso, S.; Sylantyev, S.; Angelova, P.R.; Abramov, A.Y. Inorganic Polyphosphate Regulates AMPA and NMDA Receptors and Protects Against Glutamate Excitotoxicity via Activation of P2Y Receptors. J. Neurosci. 2019, 39, 6038-6048.

89. Lin, W.; Stone, S. Unfolded protein response in myelin disorders. Neural Regen. Res. 2020, 15, 636-645 90. Raasakka, A.; Ruskamo, S.; Kowal, J.; Han, H.; Baumann, A.; Myllykoski, M.; Fasano, A.; Rossano, R.; 
Riccio, P.; Bürck, J.; et al. Molecular structure and function of myelin protein P0 in membrane stacking. Sci. Rep. 2019, 9, 642.

91. Qaswal, A.B. Quantum Tunneling of Ions through the Closed Voltage-Gated Channels of the Biological Membrane: A Mathematical Model and Implications. Quantum Reports 2019, 1, 219-225.

92. Ingber, L. Quantum calcium-ion interactions with EEG. Sci 2019, 1, 7

93. Nagini, S.; Sophia, J.; Mishra, R. Glycogen synthase kinases: Moonlighting proteins with theranostic potential in cancer. Semin. Cancer Boil. 2019, 56, 25-36.

94. Elbaz, B.; Popko, B. Molecular Control of Oligodendrocyte Development. Trends Neurosci. 2019, 42, 263277

95. Chamberlain, K.A.; Sheng, Z.-H. Mechanisms for the maintenance and regulation of axonal energy supply. J. Neurosci. Res. 2019, 97, 897-913.

96. Cohen, C.C.H.; Popovic, M.A.; Klooster, J.; Weil, M.-T.; Mobius, W.; Nave, K.-A.; Kole, M.H.P. Saltatory Conduction along Myelinated Axons Involves a Periaxonal Nanocircuit. Cell 2020, 180, 311-322.

97. Seixas, A.I.; Azevedo, M.M.; Paes de Faria, J.; Fernandes, D.; Mendes Pinto, I.; Relvas, J.B. Evolvability of the actin cytoskeleton in oligodendrocytes during central nervous system development and aging. Cell. Mol. Life Sci. 2019, 76, 1-11

98. Kelly, J.F.; Sankaranarayanan, H.; Meerschaert, M.M. Boundary Conditions for Two-sided Fractional Diffusion. J. Comp. Phys.2019, 376, 1089-1107.

99. Ohno, N.; Ikenaka, K. Axonal and neuronal degeneration in myelin diseases. Neurosci. Res. 2019, 139, 4857.

100. Drapaca, C.S.; Ozdemir, S.; Proctor, E.A. A Non-local Model of the Propagation of Action Potentials in Myelinated Neurons. Emerg. Sci. J. 2020, 4, 148-164. 